\title{
Reconstructing the Origins of a Neuropeptide Signaling System Using the Accelerated Evolution of Biodiverse Cone Snail Venoms
}

Authors: Thomas Lund Koch ${ }^{1}$, Iris Bea L. Ramiro' ${ }^{1}$, Paula Flórez-Salcedo², Ebbe Engholm¹,3,

5 Knud Jørgen Jensen ${ }^{3}$, Kevin Chase ${ }^{4}$, Baldomero M. Olivera ${ }^{4}$, Walden Emil BjørnYoshimoto $^{1 \&}$, and Helena Safavi-Hemami ${ }^{1,4,5 \&}$

${ }^{1}$ Department of Biomedical Sciences, University of Copenhagen, Copenhagen-N, 2200, Denmark

${ }^{2}$ Department of Neurobiology and Anatomy, University of Utah, Salt Lake City, UT 84112, USA

$10 \quad{ }^{3}$ Department of Chemistry, University of Copenhagen, Frederiksberg, 1871, Denmark

${ }^{4}$ School of Biological Sciences, University of Utah, Salt Lake City UT 84112, USA

${ }^{5}$ Department of Biochemistry, University of Utah, Salt Lake City UT 84112, USA

${ }^{\&}$ Corresponding authors: walden@sund.ku.dk and safavihelena@sund.ku.dk

\section{Abstract}

Somatostatin and its related peptides (SSRPs) form an important family of hormones with diverse physiological roles. The ubiquitous presence of SSRPs in vertebrates and several invertebrate deuterostomes suggests an ancient origin of the SSRP signaling system. However, the existence of SSRP genes outside of deuterostomes has not been established and the

20 evolutionary history of this signaling system remains poorly understood. Our recent discovery of SSRP-like toxins (consomatins) in venomous marine cone snails (Conus) suggested the presence of a homologous signaling system in mollusks and potentially other protostomes. Here we identify the molluscan SSRP-like signaling gene that gave rise to the consomatin family. Following recruitment into venom, consomatin genes experience strong positive selection and

25 repeated gene duplications resulting in the formation of a hyper-diverse family of venom peptides. Intriguingly, the largest number of consomatins was found in worm-hunting species (> 400 sequences), indicating a homologous system in annelids, another large protostome phylum. Comprehensive sequence mining enabled the identification of orthologous SSRP-like sequences (and their corresponding orphan receptor) in annelids and several other protostome

30 phyla. These results establish the existence of SSRP-like sequences in many major branches of bilaterians, including xenacoelomorphs, a phylum believed to have emerged before the divergence of protostomes and deuterostomes, $\sim 600 \mathrm{My}$ ago. Finally, having a large set of predator-prey SSRP sequences available, we show that while the cone snail's signaling SSRPlike genes are under purifying selection, in striking contrast, the consomatin genes experience rapid directional selection to target receptors in a changing mix of prey. 


\section{Introduction}

Small, secreted peptides form a large and diverse group of signaling molecules that are essential for fundamental biological processes. Many of these signaling peptides originated early in animal evolution with descendants found in both protostomes and deuterostomes, the two major groups of bilaterians (Jékely 2013; Mirabeau and Joly 2013). Since signaling peptides that share common ancestry often also exert similar functions, their study can provide fundamental insight into the common biology of species that span diverse phyla, e.g., from protostome model organisms, such as the fruit fly, the nematode Caenorhabditis, and the sea hare Aplysia, to deuterostomes, including zebrafish and humans. Examples of ancient signaling peptides include those of the insulin family, neuropeptide Y peptides, and oxytocin/vasopressin-like peptides (Elphick et al. 2018).

While important to know, the evolutionary origin of signaling peptides can be challenging to uncover. Because of their small size, signaling peptides often lack sufficient sequence conservation to establish homology, especially if peptides are compared between distantly related species. Additionally, many signaling peptide precursors do not contain well-defined structural or functional domains that could help in determining their relatedness. Repetitive sequence regions of varying frequency and lengths are also common, further hampering efforts to establish relatedness between signaling peptides from divergent species. Consequently, many homologous signaling peptides are diversified to a point beyond recognition, even though they share common ancestry.

There is alternative evidence that can be gathered to establish homology. For example, conserved structures of the peptide-encoding genes (the number, positions, and phases of introns) can in some cases be used to determine homology (Mair et al. 2000; Yañez-Guerra et

60 al. 2020; Zhang et al. 2020). Furthermore, comparative sequence analysis of the target receptor, which are often G protein-coupled receptors (GPCRs), can assist in establishing orthology. Because of their larger size and well-defined sequence structures, compared to their peptide ligands, GPCRs are more amendable to phylogenetic analyses. GPCR receptor-ligand pairs are typically stably associated throughout evolution. Thus, orthology between divergent signaling

65 peptide ligands may be inferred from orthologies of their receptors (Mirabeau and Joly 2013). This approach has been successfully used to find common ancestry of, for example, deuterostome gonadotropin-releasing hormone and protostome adipokinetic hormone, even though the peptide ligands themselves only share a single amino acid (Grimmelikhuijzen and Hauser 2012). Although these methods have proven successful in tracing the evolution of some 
70 signaling peptides, the origin and relatedness of many important receptor-ligand systems remains unknown.

In this paper, we use a novel approach for inferring homology based on a group of venom peptides that share sequence and functional similarity with somatostatin and its related peptides (SSRPs), a family of hormones that was until recently believed to be restricted to chordates. As

75 we show here, the venom peptides unravel the existence of an SSRP-like signaling system in protostomes and track the evolution of this system to early Bilateria.

The venom peptides used here are produced by a highly-biodiverse marine lineage, the predatory cone snails (Conus). Cone snail venoms are extremely complex, with hundreds of different components per species, which can be grouped into gene families (Woodward et al.

80 1990). Each venom peptide family has a conserved signal sequence, but the mature secreted peptide is subject to accelerated evolution, resulting in the venom of each species having its own distinctive complement of peptides (Li et al. 2017). Endogenous signaling peptides, widely distributed across all molluscs, can be recruited for expression in cone snail venom — this has previously been demonstrated for oxytocin (Cruz et al. 1987) and insulin (Safavi-Hemami et al. 2016). In a recent paper, we identified another family of signaling peptide-like toxins in Conus venom with significant sequence similarity to somatostatin (Ramiro et al. 2021). Whether these somatostatin-like cone snail toxins (consomatins) evolved from an endogenous somatostatin-like signaling peptide was not addressed.

Somatostatin (SS) is a highly conserved chordate hormone, which was initially discovered as

90 an inhibitor of growth hormone release from the hypothalamus (Brazeau et al. 1973). It has since been found to serve diverse physiological functions, including the inhibition of insulin and glucagon release from the pancreas, regulation of gut motility, and as an analgesic, anxiolytic and anticancer agent (Martinez 2015). SS was the first discovered member of a multigene family of peptides that all evolved from an ancestral SS-like gene. During chordate

95 evolution the ancestral SS gene duplicated in multiple rounds, such that there are four peptides related to SS in mammals: somatostatin (SS), cortistatin (CST), urotensin-II (UII) and urotensin-II related peptide (URP), and 8 such genes in teleost fish (Figure 1A) (Tostivint et al. 2014). SS and CST are inhibitors of hormone secretion, inflammation, and pain while UII and URP are important regulators of cardiovascular activity (Moller et al. 2003; Vaudry et al.

100 2010). Several studies have also suggested partially overlapping effects of these peptides. For example, UII is primarily known as a potent vasoconstrictor, but it also shares several functions with SS, such as inhibition of insulin secretion and regulation of food intake (Ong et al. 2008). In this article, we collectively refer to these peptides as somatostatin-related peptides (SSRPs). 
SSRPs exert their function through activating various members of the GPCR family. In humans,

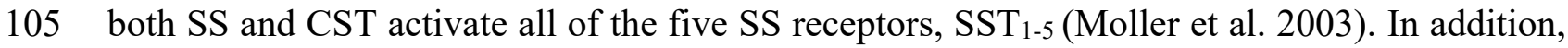
CST also activates the ghrelin receptor and Mas-Related G Protein-Coupled Receptor-X2 (MRGPRX2) (Deghenghi et al. 2001; Robas et al. 2003). UII and URP both bind to and activate the urotensin receptor (UT) (Vaudry et al. 2010). As for their ligands, $\mathrm{SST}_{1-5}$ and UT are thought to have originated from a common ancestor during chordate evolution (Tostivint et al. 2014).

110 SSRPs were initially believed to be exclusively found in chordates, but the discovery of an SSlike peptide in the starfish Asterias rubens (phylum Echinodermata) capable of activating an SST-like receptor established the presence of an SSRP signaling system in deuterostome invertebrates and suggested a more ancient evolutionary history of SSRPs (Figure 1B) (Semmens et al. 2016; Zhang et al. 2020). Furthermore, our recent discovery of consomatins in 115 the venom of fish-hunting cone snails that selectively activate different subtypes of the human $\mathrm{SST}_{1-5}$ suggested the existence of an SSRP-like signaling system in protostomes that may have given rise to the consomatin family (Figure 1C) (Ramiro et al. 2021).

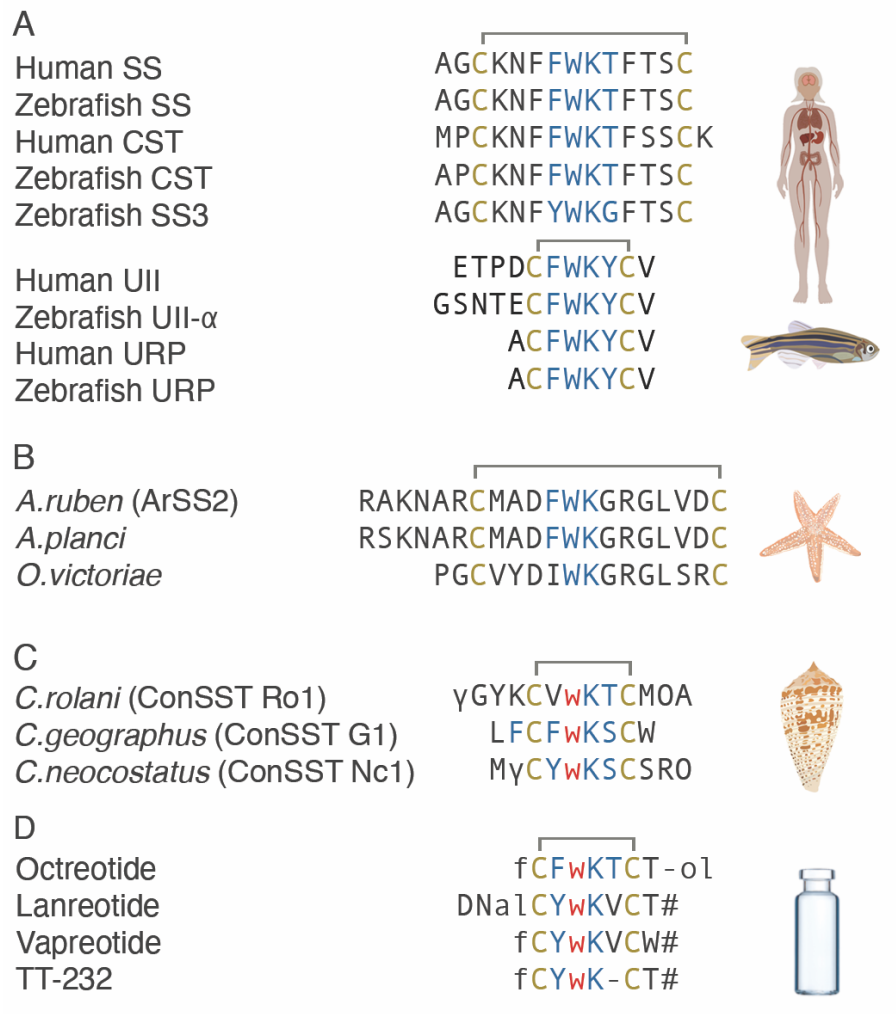

Figure 1. Somatostatin and its related peptides (SSRP) from (A) vertebrates (human and zebrafish), and (B) echinoderms, (C) consomatins from fish-hunting cone snails, and (D) therapeutic somatostatin (SS) analogs. Cysteines and amino acids of the core SS receptor binding motif are shown in yellow and blue, respectively. Modifications: $\gamma=\gamma$-carboxyglutamate; $\mathrm{w}=\mathrm{D}-$ tryptophan (shown in red); $\mathrm{O}=$ hydroxyproline, $\mathrm{f}=\mathrm{D}$-phenylalanine; \#=amidation; -ol=alcohol, $\mathrm{DNal}=3$ (2-Naphthyl)-L-alanine 
Here, by tracing the evolution of consomatins we unravel the existence of homologous peptides in diverse protostome phyla that, based on several lines of evidence, are proposed to be orthologs of chordate SSRPs. Specifically, we find that consomatins are derived from SSRP-

130 like signaling peptides that are expressed in neuroendocrine tissue of mollusks, annelids, and several other protostome phyla. The signaling SSRP-like gene experiences purifying selection to target a conserved endogenous receptor, but once duplicated and recruited into venom, rapidly diversifies to target receptors in a shifting mix of prey and, potentially, predators and competitors. Collectively, our findings shed light on the broad existence and early evolution of

135 the SSRP-like signaling system in Bilateria and provide a new paradigm for the use of animal toxins to track the evolution of important signaling systems across diverse prey taxa.

\section{Results}

\section{Evolution of diverse cone snail toxins with similarity to chordate SSRPs}

Recently, we identified and characterized a novel family of somatostatin-like toxins (consomatins) in fish-hunting cone snails of the Asprella and Gastridium clade that target the SS signaling system in vertebrates (Ramiro et al. 2021). Consomatins share several conserved

residues with chordate SSs, selectively activate different subtype of the human SS receptor, and display a minimized disulfide scaffold and a D-amino acid that is also found in synthetic SS drug analogs, such as Octreotide and Lanreotide (Figure 1C-D). In our previous study, we specifically searched for toxins that share at least three of the four residues important for activating the human SS receptor, or have conservative substitutions in these positions (residues

150 7-10: FWKT, numbering based on human SS-14). Here, to elucidate the full diversity of consomatins that not only share sequence similarity with SS but also other members of the SSRP family, we more broadly searched for sequences that display the WK motif (residues 89) and disulfide loop characteristic for these peptides (see Figure 1A).

By searching the genomes and venom gland transcriptomes of a phylogenetically diverse set of

15525 cone snail species, we identified 52 consomatin sequences containing these features (Figures 2A and S1, see Supporting File 1 and 2 for sequences and accession numbers of all datasets interrogated in this study). All sequences belong to the $\mathrm{C}$ toxin gene superfamily that is defined by a conserved N-terminal signal sequence involved in translocation to the endoplasmic reticulum and secretory pathway. 
bioRxiv preprint doi: https://doi.org/10.1101/2021.11.05.463867; this version posted November 6, 2021. The copyright holder for this preprint (which was not certified by peer review) is the author/funder, who has granted bioRxiv a license to display the preprint in perpetuity. It is made available under aCC-BY-NC 4.0 International license.

160 Consomatin genes contain 3 exons (Figure 2A): the first exon covers the signal sequence and $\mathrm{N}$-terminal part of the pro-region, the second exon encodes the C-terminal part of the proregion, as well as the N-terminal processing site and first 1-5 amino acids of the mature peptide, and the last exon spans the remaining part of the mature peptide, and in most cases a C-terminal processing site and the remaining post-peptide region. The two introns are of phase 0 and 1 , 165 respectively, with the first intron being longer.
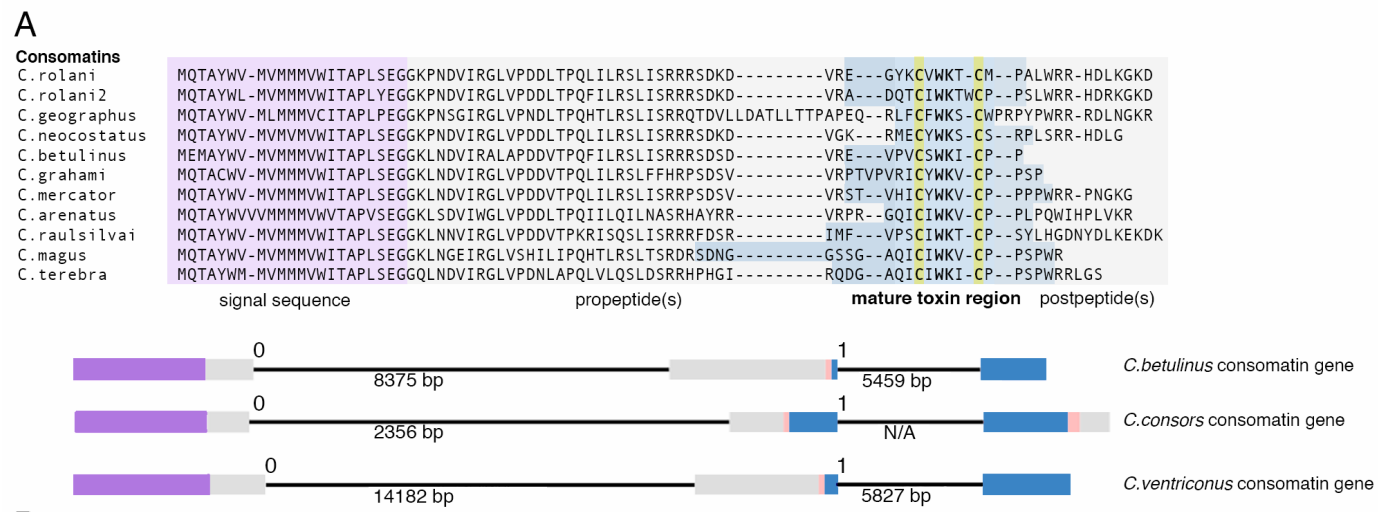

B

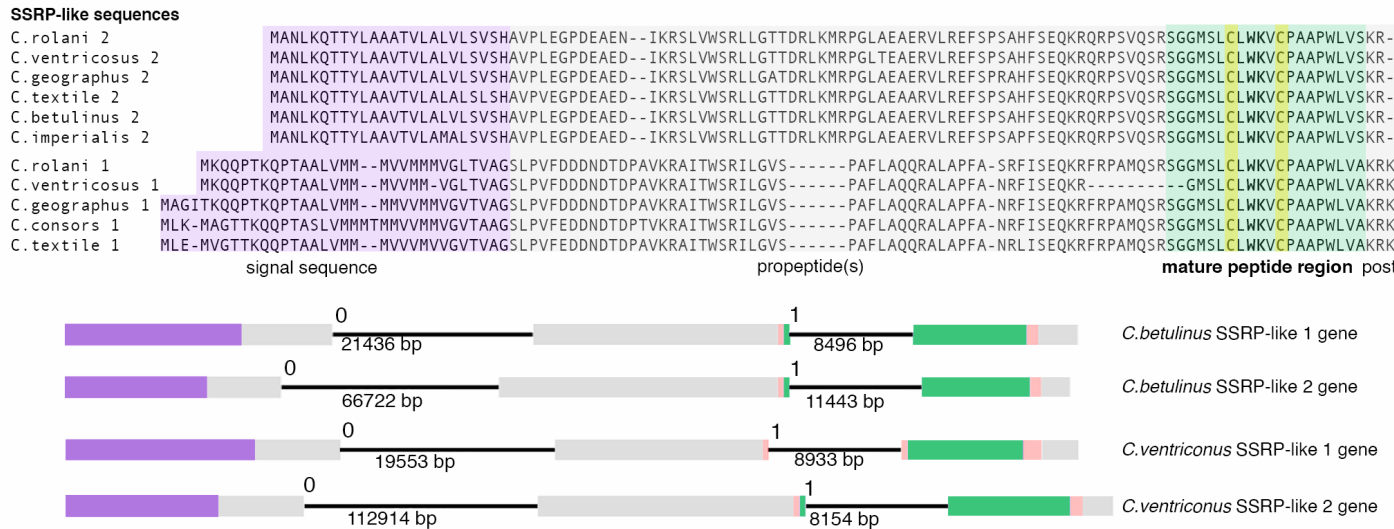

C
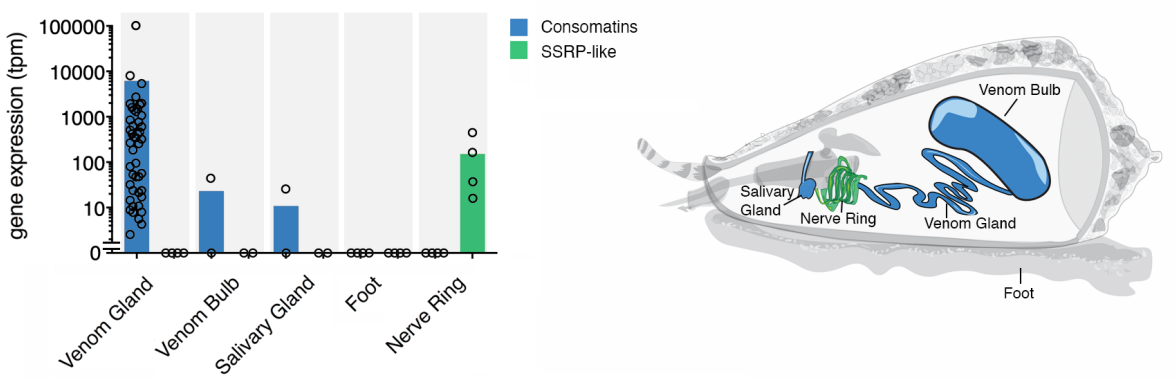

Figure 2. Consomatins and signaling SSRP-like peptides are homologs with contrasting expression patterns. Comparative sequence alignments and gene structures of selected (A) consomatins and (B) signaling SSRP-like sequences retrieved from transcriptome and genome data. The position of the signal sequence (purple), propeptides (gray), mature toxin region (blue), mature signaling SSRP-like peptide region (green), and postpeptides (gray) are shown below alignments. Gene structures are shown using the same color codes. (C) Mean gene expression levels of consomatins and signaling SSRP-like sequences in the venom gland $(n=46)$, venom bulb $(n=2)$, salivary gland $(n=2)$, foot $(n=4)$, and circumoesophageal nerve ring $(\mathrm{n}=4)$. 


\section{Consomatins evolved from an ancestral SSRP-like precursor gene}

The high sequence similarity of consomatins with chordate SSRPs suggested that these toxins may have originated from a molluscan SSRP-like gene involved in neuroendocrine signaling.

180 To investigate this possibility, we sequenced the transcriptomes of the circumoesophageal nerve ring, an arrangement of nerve ganglia known to secrete neuroendocrine signaling peptides (Safavi-Hemami et al. 2016) from four divergent cone-snail species, Conus rolani, Conus geographus, Conus textile, and Conus imperialis. Homology searching for an SSRP-like gene led to the identification of two highly expressed sequences encoding prepropeptides that share

185 the WK motif and disulfide loop with consomatins and, therefore also with vertebrate SSRPs (Figure 2B, Supporting Files 1 and 3). The two SSRP-like genes (SSRP-like 1 and SSRP-like 2) have common characteristics of peptide preprohormones (N-terminal signal sequence and canonical proteolytic processing sites), and are expressed specifically in the nerve ring, whereas consomatin sequences are expressed primarily in the venom gland, and at much lower levels in

190 the venom bulb, a muscular extension of the gland that plays a role in venom delivery, and the salivary gland, an accessory gland located in close proximity to the venom gland (Figure 2C). To specifically determine if the consomatin and the SSRP-like signaling genes evolved from a common, ancestral SSRP-like predecessor, we interrogated the available genomes of Conus betulinus, Conus consors, and Conus ventricosus. We found that the organization of the signaling genes mirrors that of the venom genes, including the number, site, and phases of the introns, and the location of the mature peptides within the genes (Figure $2 \mathbf{A}$ and B). These highly conserved structural features corroborate that consomatins evolved by gene duplication of a signaling SSRP-like gene expressed in the snail's neuroendocrine system. Whether consomatins emerged from only one or both SSRP-like signaling genes could not be

200 determined. However, as evident by phylogenetic analysis, following the duplication event(s), consomatin genes neofunctionalized and proliferated leading to a great diversification of this venom peptide family (Figure 3A). 


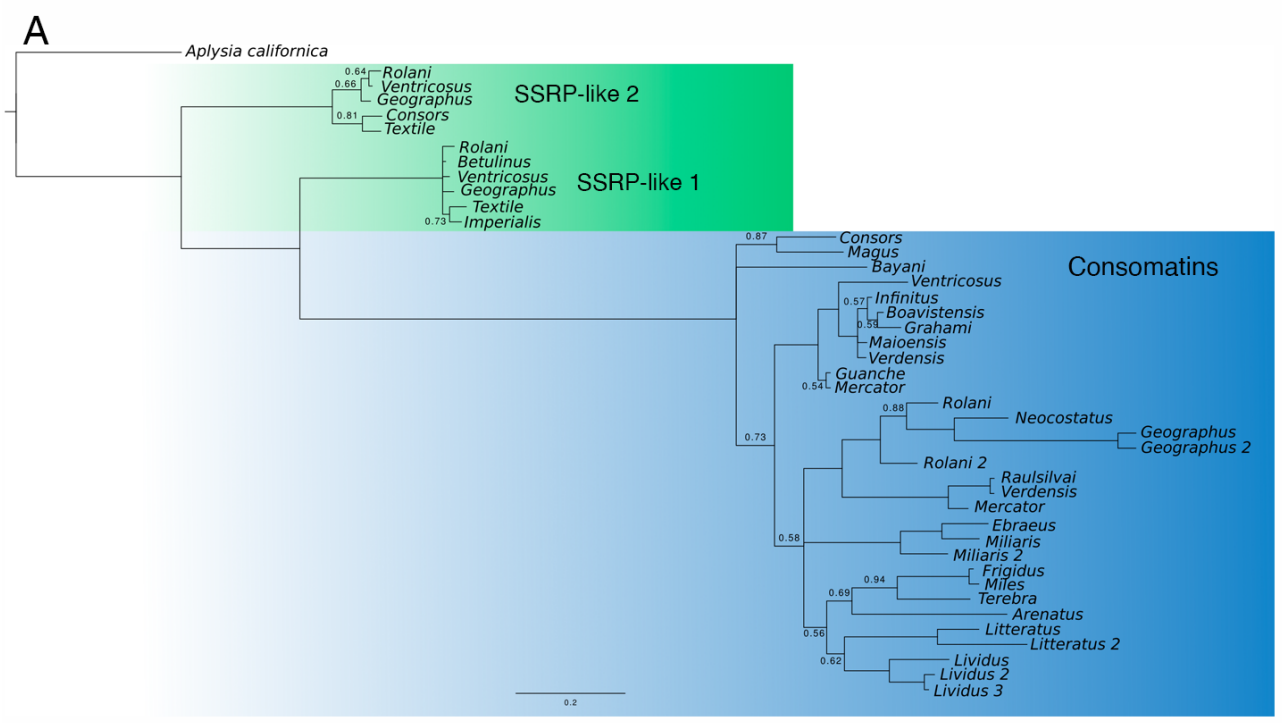

$\mathrm{B}$
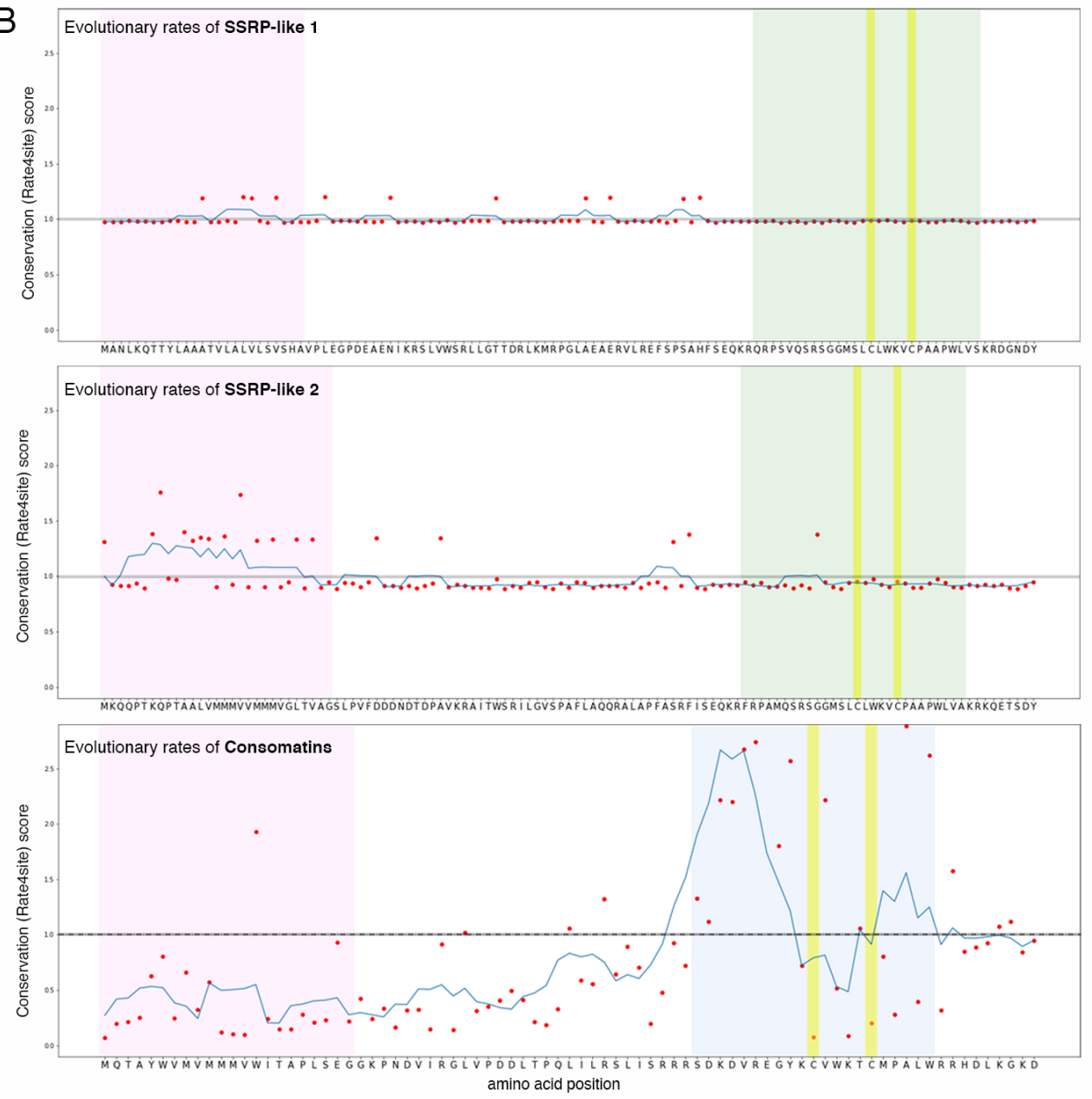

Figure 3. Consomatins and signaling SSRP-like sequences show contrasting evolutionary patterns. (A) Bayesian gene tree of consomatin and nerve ring SSRP-like sequences from diverse cone snail species. Branch lengths are proportional to estimated amino-acid change, highlighting the speed with which consomatins have diverged, as compared to the nerve ring sequences. Only posterior probabilities values below 0.95 are depicted for visual clarity. (B) Position-specific evolutionary rates of SSRP-like 1 (top), SSRP-like 2 (middle), and consomatin (bottom) sequences as determined using rate4site. Amino

210 acids of the corresponding sequences from Conus rolani are shown for clarity. Color codes are the same as in Figure 2. 


\section{Contrasting evolutionary patterns between consomatins and signaling SSRP-like genes}

In contrast to the hyper-diverse consomatin family, the two signaling SSRP-like genes are

215 almost identical to one another within and between the four different cone snail species (mean amino-acid sequence identity of $50.3 \%$ between the genes and $96.6 \%$ and $91.5 \%$ between species for each of the two genes). This is further highlighted by their close grouping and short branches in phylogenetic analyses (Figure 3A). To determine whether the signaling genes have been subject to negative/purifying selection, we estimated the pairwise $\mathrm{dN} / \mathrm{dS}$ ratios between genes from different cone snails (Supporting File 4). The $\mathrm{dN} / \mathrm{dS}$ ratio is the rate of nonsynonymous to synonymous mutations, where ratio above 1 indicates positive selection, while a ratio below 1 indicates purifying selection. Based on estimates of pairwise $\mathrm{dN} / \mathrm{dS}$ ratios, the signaling genes appear to have been subject to negative/purifying selection (SSRP-like gene 1: mean $\mathrm{dN} / \mathrm{dS}=0.34$, range: 0.08-1.20; SSRP-like gene 2: mean $\mathrm{dN} / \mathrm{dS}=0.57$, range: 0.11 -

225 1.02). This is also confirmed by comparing M7 and M8 models in the program PAML, which estimates the likelihood that some sites evolved under positive selection. This analysis showed that none of the sites appear to diverge from negative or neutral selection in any of the two genes (Table 1).

To estimate the evolutionary rate of the consomatin genes we randomly selected 20 230 transcriptome sequences. Pairwise comparison gave average $\mathrm{dN} / \mathrm{dS}=3.04$ with $88 \%$ of comparisons above 1 (Supporting File 4). Tests for positive selection (M7 vs M8) strongly favors a model, where $26 \%$ of the 62 aligned codons have evolved with an average $\mathrm{dN} / \mathrm{dS}$-ratio of 6.94, in contrast to a model constrained to negative or neutral evolution at all sites (model statistics can be seen in Table 1). Positive selection is particularly evident at sites around the 235 mature toxins, except for the cysteine residues that form the disulfide loop and the WK-motif, which are all highly conserved.

Table 1. Models and statistical values of pairwise dN/dS ratios between gene families (SSRP-like 1, SSRP-like 2, 240 and consomatins) from different cone snails.

\begin{tabular}{lllll}
\hline Gene & Model & Ln Likelihood & Parameters & Model comparison \\
SSRP-like 1 & M7 & -643.92 & 12 & \\
\hline MSRP-like 2 & M7 & -634.92 & 14 & M8 vs. M7:2 $\Delta \operatorname{lnL}=0, \mathrm{df}=2, \mathrm{p}=1$ \\
\hline & M8 & -598.79 & 12 & M8 vs. M7: $2 \Delta \operatorname{lnL}=1.66, \mathrm{df}=2, \mathrm{p}=0.44$ \\
\hline Consomatins & M7 & -1403.60 & 38 & \\
\hline & M8 & -1349.32 & 40 & M8 vs. M7: $2 \Delta \operatorname{lnL}=108.56, \mathrm{df}=2, \mathrm{p}=0.00$
\end{tabular}


Plotting the conservation (Rate4site) scores for consomatins can further be used to visualize how the different regions of the toxins precursor evolve at different rates. While the signal sequence and pro-regions are all well conserved, amino acids within the mature toxins are highly divergent, apart from the two cysteines and the WK motif. In stark contrast, the signaling SSRP-like sequences are highly conserved all throughout the preprohormone (Figure 3B-C).

\section{The signaling SSRP-like genes are ubiquitously found in all classes of mollusca}

We hypothesized that the two SSRP-like genes found in the circumoesophageal nerve ring of

cone snails encode secreted peptides involved in neuroendocrine signaling. Since signaling peptides are generally well conserved within phyla, we searched for similar genes in other mollusks. This led to identification of highly similar genes in all molluscan classes (Gastropoda, Bivalvia, Polyplacophora, Cephalopoda, Scaphopoda, Aplacophora and Monoplacophora, see Supporting File 5 for sequences). In particular, we found that the cone snail SSRP-like genes are orthologous to a previously described gene from the sea hare Aplysia californica that encodes a secreted, bioactive peptide expressed in various ganglia (buccal, cerebral, pleuralpedal and abdominal) (Romanova et al. 2012). Based on its sequence similarity to vertebrate UII this peptide was named Aplysia UII (apUII). ApUII shares $40 \%$ identity with the predicted cone snail signaling SSRP-like peptide. This finding confirms that the SSRP-like gene family

260 that gave rise to consomatins encodes a molluscan neuroendocrine peptide that shares sequence similarity with members of the chordate SSRP family. While the A. californica genome assembly was not of sufficient quality to interrogate the structure of the apUII-encoding gene, analysis of several other molluscan genomes, including that of the golden apple snail, Pomacea canaliculata, confirmed the same exon/intron structure as identified for the consomatin and the

265 cone snail signaling SSRP-like genes (Figure S2A).

\section{Consomatins expressed in worm-hunting species unravel the existence of an orthologous} signaling system in annelids

Previously, we showed that two consomatins from fish-hunting cone snails of the Asprella and

270 Gastridium clade share several important amino acids with vertebrate SSs and selectively activate the human $\mathrm{SST}_{1,4}$ and $\mathrm{SST}_{2}$ with low micromolar and low nanomolar potency, respectively (Ramiro et al. 2021). We further noticed that consomatins were also expressed in some cone snail species that prey on annelid worms which strongly suggested the existence of an SSRP-like signaling system in annelids. Here, by searching the genomes and transcriptomes 
275 of 19 species of worm-hunting cone snails we first confirm the wide distribution of consomatins in various clades of worm hunters (48 sequences from 19 species belonging to 10 clades). We then proceeded to use the molluscan signaling SSRP-like sequences to query similar genes in a wide range of annelid genomes and transcriptomes. By doing so, we find 19 SSRP-like sequences from 14 species belonging to both classes of Annelida (Polychaeta and Clitellata),

280 demonstrating the wide distribution and expression of SSRP-like genes in this large protostome phylum (Supporting File 6). Notably, SSRP-like sequences are not restricted to marine species but are, for example, also present in the earthworm Lumbricus rubella.

Several, but not all, annelid SSRP-like genes have gene structures that are identical to the molluscan counterpart: 3 exons that are separated by a phase 0 and phase 1 intron with the signal sequence located on exon 1 , and with the mature peptide starting at the 3 ' end of exon 2 and extending into exon 3, where the conserved WK-motif and disulfide loop is located (Figure S2). This gene structure and high similarity to the molluscan genes strongly suggests that these systems are orthologous. However, not all annelids strictly adhere to this canonical SSRP-like

290 gene structure. In Dimorphilus gyrociliatus, an annelid with a miniaturized genome (MartínDurán et al. 2021), two of the three SSRP-like genes lack the second intron, while in Streblospio benedicti, an annelid with an unusually large genome (Zakas et al. 2021), a third intron interrupting the signal sequence can be found (Figure S2).

295 Our findings on the existence of SSRP-like sequences in diverse classes of Mollusca and Annelida prompted us to look for similar sequences in other metazoan phyla. This search led to the identification of SSRP-like sequences in three additional phyla: Brachiopoda, Rotifera and Xenacoelomorpha (Supporting File 7, and where available their conserved genes, Figure S2). The phylogenetic position of xenacoelomorphs is still debated, but the current consensus is that 300 xenacoelomorhps are bilaterians that diverged before the major Protostomia-Deuterostomia split (Cannon et al. 2016; Hejnol and Pang 2016; Jondelius et al. 2019; Kapli and Telford 2020). Notably, SSRP-like peptides appear to be absent from ecdyzozoans, a group of protostomes that includes nematode worms and arthropods. Thus, SSRP-like sequences are found across many but not all branches of bilaterians (Figure 4). 


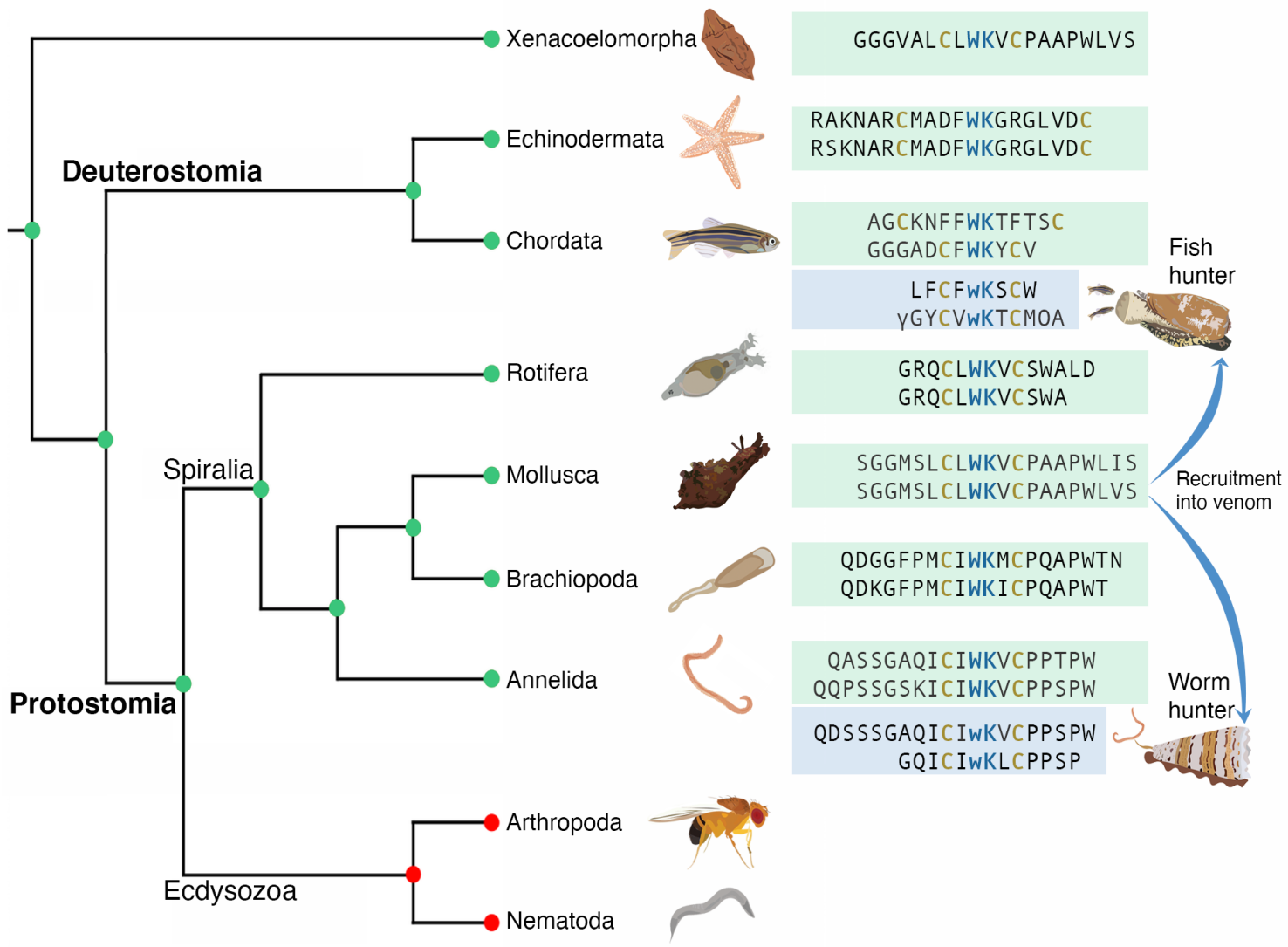

Figure 4. Distribution and selected sequences of SSRP-like genes in diverse bilaterian phyla. Cladogram showing proposed retention (green circles) and loss (red circles) of the SSRP-like gene across diverse animal phyla. Green boxes show select sequences of signaling SSRP-like genes, blue boxes depict highly similar consomatin sequences identified in fish- and worm-hunting species of cone snails. Sequences (from top to bottom): Xenoturbella bocki, Asterias rubens (ArSS2), Acanthaster planci (Apla_2), Homo sapiens (SS, identical sequence present in Danio rerio), Danio rerio (UII), Conus geographus (consomatin G1), Conus rolani (consomatin Ro1), Rotaria sordida, Rotaria tardigrada, Aplysia californica (apUII), Conus textile, Linguna anatina, Linguna anatina 2, Capitella teleta (SSRP-like peptide 1), Platynereis dumerilii, Conus floridulus (consomatin Fr1), Conus tribblei 315 (consomatin T11). Modifications: $\gamma=\gamma$-carboxyglutamate; $\mathrm{w}=\mathrm{D}$-tryptophan; $\mathrm{O}=$ hydroxyproline.

\section{Protostome SSRP-like peptides activate receptors that share sequence similarity with chordate somatostatin receptors}

320 To further investigate the function of protostome SSRP-like sequences, we synthesized the predicted mature peptides of Ct-SSRPL1 from the genome and whole-body transcriptome of the annelid Capitella teleta and Cr-SSRPL1 from the nerve ring transcriptome of Conus rolani and tested them at their predicted receptor pairs; an annelid candidate receptor from the transcriptome of C. teleta (Ct-SSTL1), and a molluscan candidate receptor from the Conus

325 betulinus genomic DNA assembly (Cb-SSTL1). These orphan receptors grouped with the human SSTs in maximum likelihood tree analyses, suggesting that they are members of an invertebrate SSRP signaling system (Figure 5A and S3). We note that the molluscan receptors 
with the highest sequence similarity to the chordate SS receptors are allatostatin C (ASTC) receptors (Figure 5A). ASTCs are protostome peptides with some resemblance of SS (a Con the similarity of their receptors to the SS receptor and their inhibitory functions (Mirabeau and Joly 2013; Veenstra 2009). ASTC is also present in mollusks (Zhang et al. 2018), but while we could identify ASTC in the cone snail nerve ring transcriptomes (data not shown) the ASTC ligand-receptor system was not further investigated here.
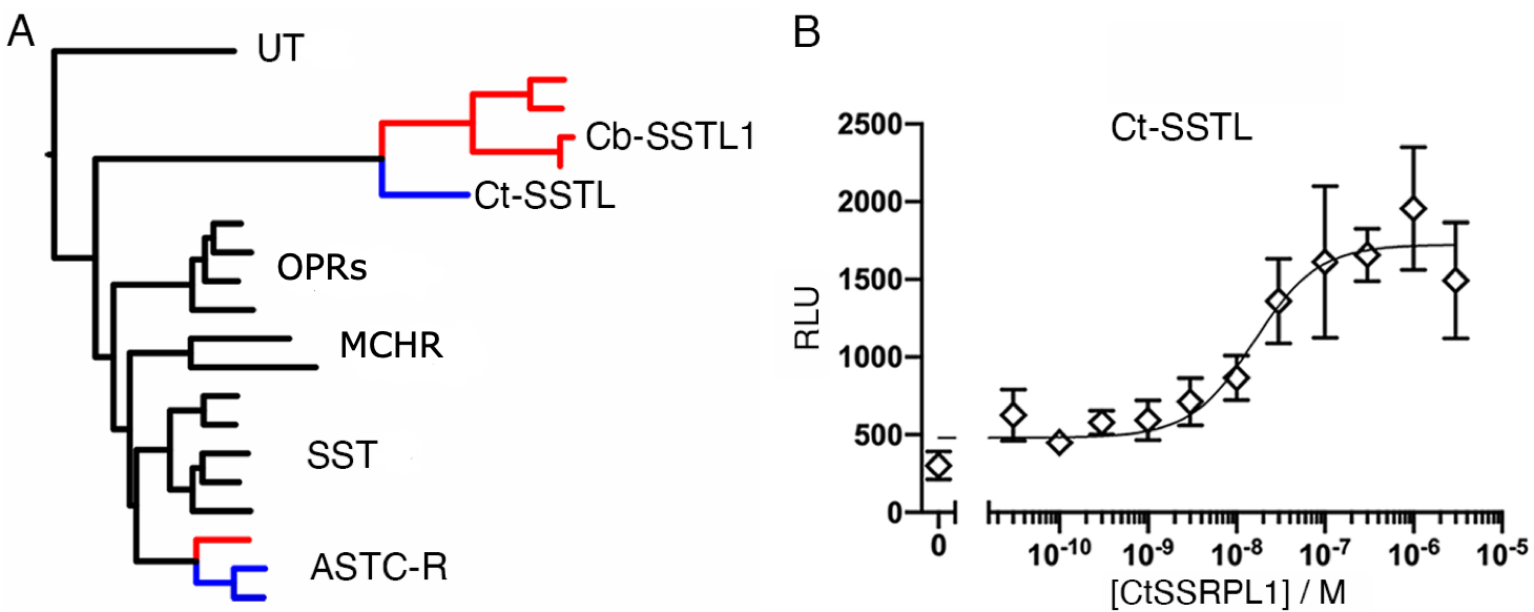

Figure 5. Ct-SSL1 clusters with human SSRP and related receptors and is activated by Ct-SSRP1. (A) Maximum likelihood tree analysis of human SSRP receptors (SST and UT) and closely related receptors (Opioid receptors (OPRs) and melanin-concentrating hormone receptors (MCHR)) and the

340 ASTC-R from the annelid Platynereis dumerilli with orphan receptors from Conus betulinus (red branches) and Capitella teleta (blue branches). The tree was rooted with human galanin and kisspeptin receptors (not shown). The location of Ct-SSTL1 and Cb-SSTL1 are shown. The full tree with bootstrap values and labels can be found in Figure S3. (B) Concentration-response curve of Ct-SSRPL1 at the CtSSTL1 receptor in the PRESTO-Tango assay (error bars represent SD). The experiment was performed 345 in three independent repeats, and the mean $\mathrm{EC}_{50}$ value was $13.1 \mathrm{nM}(\mathrm{pEC} 50 \pm \mathrm{CI} 95=7.88 \pm 0.65)$.

The C. teleta peptide, Ct-SSRPL1, showed strong activation of its predicted receptor, CtSSTL1, with an $\mathrm{EC}_{50}$ of $13.1 \mathrm{nM}(\mathrm{pEC} 50 \pm \mathrm{CI} 95=7.88 \pm 0.65)$ (Figure 5B). This finding 350 suggests that the Ct-SSTL1 receptor is indeed the functional target of this peptide. In contrast, the cone snail peptide, Cr-SSRPL1, showed no robust response at its predicted receptor, indicating that this receptor may not represent the biological target of this peptide or that the receptor was not expressed in its functional form (data not shown). However, when applied to the Ct-SSTL1 receptor at $30 \mu \mathrm{M}$, the highest concentration tested, Cr-SSRPL1 showed 355 approximately $50 \%$ activation, and was also able to activate the human $\mathrm{SST}_{2}$ with micromolar potency (Figure S5). 
bioRxiv preprint doi: https://doi.org/10.1101/2021.11.05.463867; this version posted November $6,2021$. The copyright holder for this preprint (which was not certified by peer review) is the author/funder, who has granted bioRxiv a license to display the preprint in perpetuity. It is made available under aCC-BY-NC 4.0 International license.

\section{Consomatins evolve to target the SSRP-like signaling system in prey}

Collectively, our findings suggest that early in the evolution of cone snails, a duplicated SSRPlike gene that functions in neuroendocrine signaling in many bilaterians was recruited for expression in the venom gland. As cone snails radiated and diversified ecologically, the venom gene greatly proliferated and diverged in sequence.

A

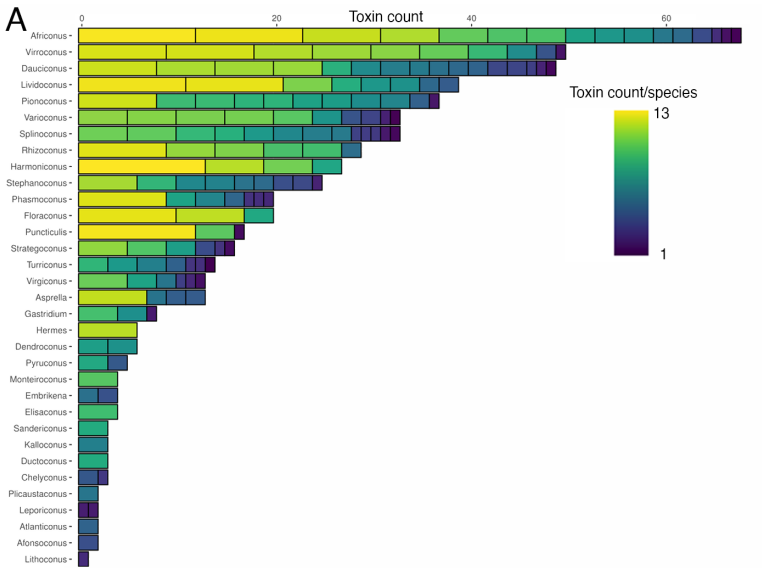

C

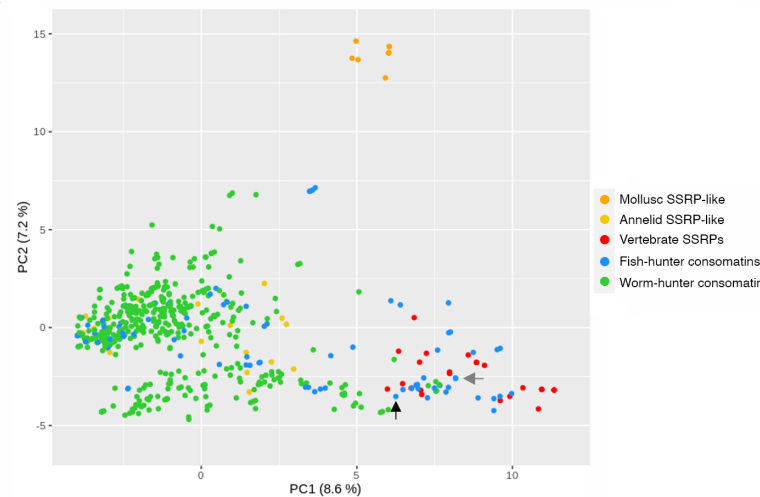

$\mathrm{B}$

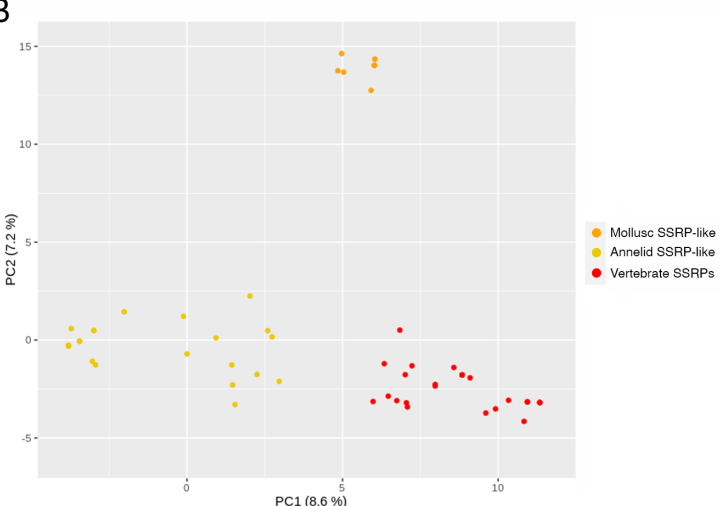

D

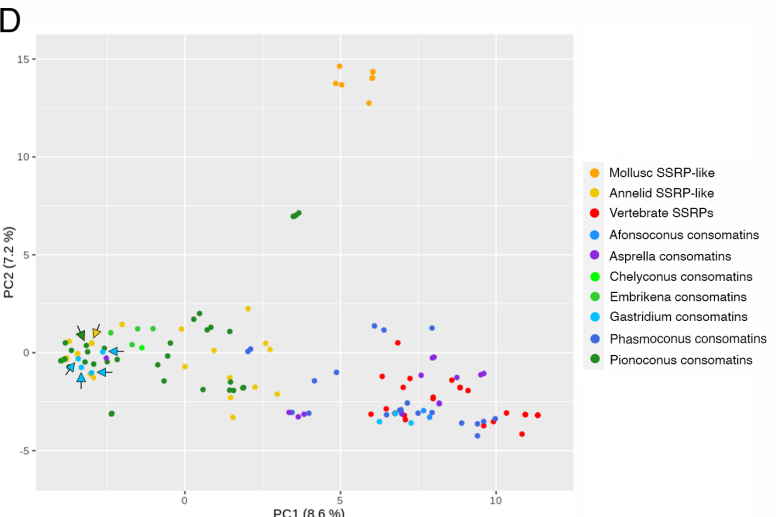

Figure 6. Diversity of consomatins and their correlation with prey peptides. (A) Bar graph of the consomatin count in the different cone snail lineages investigated in this study. Each bar is comprised of smaller elements representing the individual species of the lineage. Both the length and color of smaller bars represents the number of consomatins. Consomatins could not be identified in the following lineages: Fraterconus, Klemaeconus, Lindaconus, Textilia, Tesselliconus, and all 5 lineages of snail hunters included here: Eugeniconus, Conus, Leptoconus, Darioconus and Cylinder. (B) Principal component analysis (PCA) of characteristics of vertebrate SSRPs, annelid and molluscan SSRP-like sequences. (C) Same analysis as in (B) including consomatins from fish-and worm-hunting cone snails. (D) PCA showing SSRPs and SSRP-like signaling peptides from vertebrates, annelids, and mollusks as well as consomatins from fish-hunters separated into clades.

The prey of ancestral cone snails were polychaete worms (Duda et al. 2001; Puillandre et al. 2014). Some cone-snail lineages later shifted to prey on mollusks, and others on fish (Kohn 1956; Olivera et al. 2015; Puillandre et al. 2014). Having established the existence of SSRP- 
380 like sequences in these diverse prey taxa allowed us to test if the great diversification of consomatins occurs in response to biotic interactions with different prey. In other words, if consomatins target the SSRP-like receptor of prey species, then they would be expected to resemble the native (signaling) SSRP-like peptides of those prey species. To investigate this hypothesis, we performed principal component analysis (PCA) of vertebrate SSRPs (including

385 fish and human sequences), signaling SSRP-like sequences from mollusks and annelids as well as a large set of consomatins. PCA transforms a large group of correlated variables into a smaller set of uncorrelated variables (the principal components) that are more easily interpretable. Here, the scored variables included length, aromaticity, molecular weight, isoelectric point, and count of the 150 most common 1-3mers (see Material and Methods).

390 Because we established that the mature region of consomatins is almost exclusively located on a single exon (exon 3) we were able to utilize recent exon capture data of this exon from 247 distinct species of cone snails representing all major branches of the Conus phylogenetic tree (Phuong et al. 2019) (see Table S1 for all species and accession numbers used in this study). Using these datasets, we identified 502 consomatin genes of which 71 and 431 were from 30

395 fish-hunting and 131 worm-hunting species, respectively (Supporting File 8). Consistent with transcriptome analysis, consomatin genes greatly proliferated in some lineages (e.g., Africonus, Virroconus, Dauciconus, and Lividoconus), and were seemingly lost in others (e.g., Textilia and Tesseliconus) (Figure 6A). Interestingly, consomatin genes could not be detected in any of the 22 snail-hunting species analyzed. This may point to a loss of this gene during the shift from

400 worm- to snail-hunting behavior which is believed to have only occurred once (Duda et al. 2001).

In analyses of the signaling SSRP-like gene alone, the first two principal components separate sequences from mollusks, annelids, and vertebrates into distinct clusters (Figure 6B). In analyses of the signaling SSRP-like peptides together with the consomatin sequences, 405 consomatins noticeably group away from the molluscan signaling genes they derived from, andx towards the annelid and vertebrate sequences (Figure 6C). This pattern is consistent with the hypothesis that consomatins diverged to target SSRP-like receptors in prey. Indeed, consomatin sequences from fish hunters, that were previously shown to selectively target different subtypes of the human SST receptors, closely group with vertebrate SSRPs, including 410 those from fish and human (see black and gray arrows for consomatin G1 and Ro1, respectively, Figure 6C). In contrast, consomatins identified from worm hunters cluster almost exclusively towards the annelid SSRP-like sequences, again suggesting that consomatins evolve to target the SSRP-like signaling system of specific prey. Notably, a small number of consomatins from 
the worm-hunter, Conus glaucus, and several worm-hunting species of the Africonus clade are

415 placed in the vertebrate region of the plot potentially indicating that these species may also prey on fish (as observed for some other worm hunters (Aman et al. 2015)) or may use these toxins for defensive purposes.

Except for these sequences, all other consomatins that group with vertebrate SSRPs are from fish-hunting species. This not only includes consomatins from C. rolani (Asprella clade) and

420 C. geographus (Gastridium clade) known to activate the human SS receptors (Ramiro et al. 2021), but also sequences retrieved from other species belonging to these two clades (Figure 6D). Additionally, sequences from two other phylogenetically distinct clades of fish hunters, Phasmoconus and Afonsoconus, also group closely with vertebrate SSRPs. This includes the sequence of a recently identified consomatin from Conus ochroleucus (Phasmoconus) that is nearly identical to the SS drug analog octreotide and potently activates the human $\mathrm{SST}_{1-4}$ (Acaytan et al., unpublished). Thus, PCA analysis and comparative sequence analysis highlight how some, but not all fish hunters adapted the duplicated signaling SSRP-like gene to specifically target the receptors of their fish prey.

Notably, a large number of consomatins from fish hunters do not cluster with chordate SSRPs 430 but with those from annelids. Most of these sequences belong to a single clade, Pionoconus, that comprises some of the best studied cone snail species. Interestingly, this clade includes Conus magus, a species that is known to prey on annelids as a juvenile (Nybakken and Perron 1988), indicating that its consomatin sequence may have adapted to target the SSRP-like receptor in annelid prey, and possibly, that other members of this clade also prey on annelids

435 as juveniles. Grouping of the C. magus peptide with SSRP-like sequences identified in annelids that are closely related to the prey of juvenile $C$. magus strongly supports this hypothesis (see green and yellow arrows in Figure 6D representing the C. magus and the annelid C. teleta sequence, respectively).

Finally, we note that the position of consomatins from fish hunters in the PCA plot also appears

440 to correlate with predation strategy. All members of the Pionoconus clade are all taser-andtether hunters, a predation strategy characterized by a rapid immobilization of prey facilitated by the action of toxins that rapidly modulate ion channels of the nervous and locomotor systems (Olivera et al. 2015). In contrast, species of the Asprella clade, and potentially also the Phasmoconus clade, are ambush-and-assess hunters, a hunting strategy that is characterized by 445 a very slow onset of action of their toxins (Ramiro et al. 2021). The third predation strategy, net-hunting, in which toxins are released into the water, has only been observed in Gastridium clade and suggested to be used by some Afonsoconus species (Ahorukomeye et al. 2019). The 
PCA analysis reveals a clear pattern: sequences derived from taser-and-tether hunters group with annelid SSRP-like sequences, whereas toxins from net or ambush-and-assess hunters

450 group with vertebrate SSRPs (Figure 6D). PCA grouping according to predation strategy, rather than phylogeny alone, is best illustrated by two closely related species of the Gastridium clade: consomatins from Conus obscurus, a taser-and-tether hunter (Olivera et al. 2015), closely groups with the annelid sequences (light blue arrows in Figure 6D) whereas consomatins from the net-hunter C. geographus group with vertebrate SSRPs. Based on this pattern it can be

455 hypothesized that many, if not all, taser-and-tether hunters prey on annelids in their early developmental stages.

\section{Discussion}

Our investigations into the evolutionary origin of consomatins exposed the existence of an

460 SSRP-like signaling system in diverse protostome phyla that gave rise to the consomatin family. Several lines of evidence suggest that this signaling system shares a common origin with chordate SSRPs, a family of peptide hormones that includes SS, CST, UII, and URP, and their respective receptors, which in humans is the $\mathrm{SST}_{1-5}$ and the UT.

First, all protostome sequences discovered here share the conserved WK motif known to be of critical importance for $\mathrm{SST}_{1-5}$ and UT activation (Figure 4) (Moller et al. 2003). We note that the residue preceding this motif in deuterostomes is almost always aromatic (Phe or Tyr) but aliphatic in protostomes (Ile or Leu) pointing towards important differences in the receptor binding mode of the protostome and deuterostome peptides.

Second, all sequences display two cysteine residues that can form a disulfide bond. Notably,

470 the size of the disulfide loop appears conserved in all protostomes (4 residues including the WK motif) but varies in deuterostomes: while UII and URP share the loop size with protostome SSRP-like peptides, SS and CST display extended loops with 10 or 12 residues in chordates and starfish, respectively (Figure 4). If, as we propose here, the protostome and deuterostome systems are indeed related, following multiple rounds of whole genome duplication in 475 chordates, UII and URP retained the ancestral loop size while SS and CST did not. We suggest that loop size correlates with structural stability but does not directly correlate with biological activity. Shorter loop sizes have been successfully introduced in therapeutic SS analogs to improve the in vivo half-life of these analogs while retaining and in some cases improving biological activity at some SS receptor subtypes (Pless 2005). 
480 Third, when screened against the five subtypes of the human SS receptors, the neuroendocrine molluscan SSRP-like peptide exhibited micromolar activity at the human $\mathrm{SST}_{2}$, indicating that the ligands of the human and molluscan receptors are functionally related (Figure S5).

Fourth, mining the genome of the model annelid C. teleta for an SS-like receptor led to the discovery of a receptor that clusters with human SSRP receptors and that, when expressed in 485 human HEK cells and tested using the PRESTO-Tango assay, is potently activated by the $C$. teleta SSRP-like peptide 1 identified here $\left(\mathrm{EC}_{50}=13.1 \mathrm{nM}\right)$.

Finally, the ability of consomatins from some fish-hunting cone snails to activate various subtypes of the human SS receptor (Ramiro et al. 2021) strongly suggests that the molluscan, and thereby protostome SSRPs-like peptides are not only related to chordate SSRPs but can be 490 adapted to potently and selectively activate the chordate SS receptors.

Even though these lines of evidence strongly suggest a common ancestry of chordate SSRPs and protostome SSRP-like peptides, we note that other observations are less conclusive. The gene structures of protostome SSRPs differ from those observed for members of chordate

495 SSRPs. Genes of human SS and CST only have a single phase 0 intron, while those encoding UII and URP contain a single phase 0 intron and 2-3 additional phase 1 introns (Figure S2). The echinoderm SS-like genes mirror SS and CST with a single phase 0 intron (Figure S2). It was previously proposed that an $\mathrm{N}$-terminal phase 0 intron is a conserved characteristic of the SSRP gene family (Zhang et al. 2020). While all protostome SSRP-like genes identified here 500 indeed share the phase 0 intron with SS/CST and one phase 1 intron with UII/URP, considering the varying gene structure of the chordate hormones, this is only a weak indicator of common ancestry.

Additionally, while we were able to show potent activation of an annelid GPCR related to the chordate SS receptors upon application of an annelid SSRP-like peptide (Figure 5), we were not able to identify the endogenous target receptor of molluscan SSRP-like peptides. While we have tested several additional molluscan receptor candidates with sequence similarity to the chordate SS receptor and the annelid SSRP-like receptor, we could not detect any activation of these receptors by the molluscan or annelid SSRP-like peptide, or peptides of the human SSRP family (data not shown). Whether the lack of activity is due to the type of assay used here, the 510 identity and biology of the proposed target receptors, or to an incorrectly predicted mature SSRP-like peptide remains to be determined. 
However, if, as we propose here, the protostome SSRP-like signaling peptides and consomatins are indeed related to chordate SSRPs, some of these peptides could potentially be new ligands

515 of chordate receptors known to be activated by members of the SSRP family, namely the $\mathrm{SST}_{1}$ 5, the UT, the ghrelin receptor and the MRGPRX2. This may particularly be the case for members of the highly diversified consomatin family. Previously, we showed that some consomatins from fish-hunters activate different subtypes of the human SS receptor and provide new drug leads for pain and neuroendocrine tumors (Ramiro et al. 2021). Here, we provide $>500$

520 additional consomatin sequences from diverse species of cone snails for future receptor target identification and biomedical exploration.

We note that the evolution of consomatins closely resembles that of cone snail venom insulins, toxins that induce dangerously low blood sugar by activating the insulin receptor of prey: once recruited into venom, cone snail insulins experience strong positive selection resulting in a hyper-diverse family of weaponized hormones (Safavi-Hemami et al. 2016). As observed for venom insulins, consomatins of fish-hunters tend to resemble the signaling SSRP-like sequences of fish. Likewise, consomatins expressed in worm hunters tend to be similar to those found in annelids. This pattern is consistent with the hypothesis that many if not all venom insulins and consomatins are used in prey capture, and as a consequence, they are strongly selected to interact with receptors that appear regularly in a snail's diet. Furthermore, because of their streamlined role in predation, these weaponized hormones display certain properties that their signaling counterparts may not: unlike human insulin, weaponized insulins from Conus tulipa and C. geographus act rapidly because they do not self-associate into dimers and

535 hexamers (Ahorukomeye et al. 2019; Menting et al. 2016), and, unlike human somatostatin, consomatins from C. rolani and C. geographus are highly stable and selective for certain SST receptor subtypes (Ramiro et al. 2021). Thus, weaponized hormones evolved advantageous properties that can inform on the design of new drug leads for diseases associated with native human hormones (Ramiro et al. 2021; Xiong et al. 2021; Xiong et al. 2020).

Additionally, we provide a set of new SSRP-like signaling sequences from various bilaterian phyla, including some invertebrate animal models such as P.dumerilli. Based on several observations we believe that this signaling system not only exists in these animals but plays important physiological roles. First, SSRP-like sequences were recovered from several 545 transcriptome datasets demonstrating that these genes are actively expressed. Second, all these sequences have an $\mathrm{N}$-terminal signal sequence and are therefore secreted to likely function in 
neuroendocrine signaling events. One member of the SSRP-like family, namely apUII from $A$. californica, has already been shown to be secreted in the nervous system where it exerts inhibitory effects on motor programs involved in feeding (Romanova et al. 2012). Others are likely to also serve important functions. Third, the broad presence and targeted use of consomatins by worm-hunting cone snails strongly suggests an important functional role of the SSRP-like signaling systems in annelids. Lastly, the existence and expression of an annelid SSlike receptor (Ct-SSTL1) that can be potently activated by the $C$. teleta SSRP-like 1 peptide further supports an important physiological role of this signaling system. Understanding the

555 functional role of these peptides in protostomes may provide new opportunities to study the SSRP-like signaling system in invertebrate model organisms, such as C. teleta and $A$. californica. Similarly, elucidating the function of SSRP-like peptides in xenacoelomorhps may provide fundamental insight into the biological role of the ancestral SSRP-like signaling system in animals which may ultimately expand our current understanding of the diverse physiological roles of SSRP in humans.

Finally, we provide a new paradigm for the discovery of novel signaling systems based on peptide toxins that specifically evolved to target such systems. With the growing availability of large peptide toxin databases by transcriptome and genome sequencing we anticipate that this approach will be used to identify other important signaling system in the future.

\section{Acknowledgements:}

We thank Kasper Kildegaard Sørensen for help with peptide synthesis, Noel Saguil for assistance with field collections, Maren Watkins for insightful discussions, and the High Throughput Genomics Core Facility at the University of Utah, USA for library preparation and transcriptome sequencing.

\section{Funding:}

575 This work was supported by a Villum Young Investigator Grant (19063 to H.S-H.); a Starting Grant from the European Commission (ERC-Stg 949830 to H.S-H.); and a National Institutes of Health Grant (GM048677 to B.M.O.). 


\section{Materials and Methods}

\section{Transcriptome sequencing}

Specimens of C. textile, C. striatus and C. imperialis were collected in Oahu, Hawai, USA. C. rolani and C. geographus specimens were collected in Cebu, Philippines under the Department of Agriculture - Bureau of Fisheries and Aquatic Resources-issued gratuitous permit no. GP-

585 0084-15. Total RNA was extracted from the circumoesophageal nerve rings, salivary gland, venom bulbs, and foot using the Direct-zol RNA extraction kit (Zymo Research), with oncolumn DNase treatment, according to the manufacturer's instructions. Library preparation and sequencing were performed by the University of Utah High Throughput Genomics Core Facility as previously described (Ahorukomeye et al. 2019). Briefly, paired-end sequencing was performed on an Illumina HiSeq2500 or NovaSeq 6000 instrument. Adapter trimming of demultiplexed raw reads was performed using fqtrim (v0.9.4), followed by quality trimming and filtering using prinseq-lite (Schmieder and Edwards 2011). Error correction was performed using the BBnorm ecc tool, part of the BBtools package (open source software, Joint Genome Institute). Trimmed and error-corrected reads were assembled using Trinity (version 2.2.1)

595 (Grabherr et al. 2011; Haas et al. 2013) with a k-mer length of 31 and a minimum k-mer coverage of 10. Expression levels were calculated as transcripts per million (tpm). Tpm values were calculated using the RSEM program (Li and Dewey 2011). (Supporting File 1).

\section{Transcriptome assemblies and analyses}

600 Raw sequencing data of publicly available cone snail venom gland transcriptomes were retrieved from the $\mathrm{NCBI}, \mathrm{DDBJ}$ and the $\mathrm{CNGB}$ sequence repositories, and assembled using the same methods as described for tissues sequenced in this study. The list of all transcriptomes used in this study is provided in Supporting File 1. Consomatin sequences were identified from these datasets based on tblastn with sequences from (Ramiro et al. 2021) using e-value of 0.1.

605 Sequences with the C-terminal C.WK.C-motif were identified as consomatins.

\section{Gene structure analysis}

The location, size, and phases of introns were identified using the online version of Splign (Kapustin et al. 2008). Signal sequences were calculated using either command-line or online versions of SignalP 5.0 (Almagro Armenteros et al. 2019). 


\section{Phylogenetic analysis}

Multiple sequence alignments of protein sequences were performed using MAFFT v 7.310

615 (Katoh and Standley 2013). The tree in Figure 3A was constructed using a Bayesian analysis of phylogeny with Mr. Bayes v.3.2.6 (Huelsenbeck and Ronquist 2001; Ronquist and Huelsenbeck 2003) with mixed amino acid models. The analysis was performed with two runs of four Markov chains for 1,000,000 generations at which point the two chains had converged. The first $25 \%$ of samples were discarded as burn-in. The tree uses the signaling SSRP-like 620 precursor from Aplysia californica as an outgroup. The tree in Figure 5A and S3 was constructed using maximum likelihood with the program IQ-TREE v1.6.1 (Chernomor et al. 2016; Nguyen et al. 2015). The program chose the model of evolution according to the Bayesian information criterion, which was $\mathrm{LG}+\mathrm{F}+\mathrm{I}+\mathrm{G} 4$. The tree was rooted with human galanin and kisspeptin receptors, which form a known outgroup of the SSRP receptors.

\section{Selection analysis}

Signaling SSRP-like genes were extracted from the nerve ring transcriptomes of C. rolani, $C$. geographus, C. textile, and C. imperialis and from the genomes of $C$. ventricosus, and $C$. betulinus. Twenty random toxin genes were obtained from NCBI GenBank (Supporting file 2).

630 The three groups of the toxin genes and the two signaling genes were all analyzed separate and identically as follows: First, the amino acid sequences were aligned using ClustalO v 1.2.4 (Sievers et al. 2011). The amino acid alignment was then converted to the corresponding nucleotide alignment using the program PAL2NAL (Suyama et al. 2006) with the flag '-nogap'. The synonymous and non-synonymous substitutions were calculated from this codon alignment

635 with the program codeml (v4.9) from PAML (Yang 2007) under the F3x4 model of evolution. We calculated the likelihood of several different models of evolution, including pairwise comparisons of all sequences, a beta distribution of $\mathrm{dN} / \mathrm{dS}$ between 0 and 1 (M7), and a beta distribution of $\mathrm{dN} / \mathrm{dS}$ with positive selection at some sites (M8). Conventional likelihood ratio tests were used by comparing the M7 and M8. The sites with positive selection were estimated

640 with the Bayes empirical Bayes analysis.

The conservation scores for the different groups (signaling SSRP-like and consomatins) were calculated with the program rate4site (Mayrose et al. 2004) using an alignment generated by ClustalO v 1.2.4 and a maximum likelihood tree generated by IQ-tree using the same alignment. The conservation score for each site is visualized with a sliding window of 5 amino acids in the 645 figure. 


\section{Consomatin exon recovery and principal component analysis}

The SRA datasets of cone snails from Bioproject PRNJ526781 were downloaded from NCBI in September 2021 with fastq-dump 2.8.2 (SRA toolkit development team

650 https://trace.ncbi.nlm.nih.gov/Traces/sra/sra.cgi?view=software). The individual dataset was then preprocessed with fastp v.0.20.1 (Chen et al. 2018) to filter out low quality reads and were converted to fasta-format with EMBOSS seqret v. 6.6.0.0 (Madeira et al. 2019). To identify reads encoding consomatins we used the toxin sequences from earlier identified consomatins as queries in a tblastn search against the database using an e-value of 10 . The hits were then

655 assembled using Trinity v.2.13.2 (Grabherr et al. 2011; Haas et al. 2013) as single reads. The generated contigs were translated in all reading frames using EMBOSS getorf v.6.6.0.0 (Madeira et al. 2019). The putative toxins were extracted with the regular expression ${ }^{\prime}\left[{ }^{\wedge} \mathrm{C}\right]\{0,2\} \mathrm{C}\left[{ }^{\wedge} \mathrm{C}\right] \mathrm{WK}\left[{ }^{\wedge} \mathrm{C}\right] \mathrm{C}\left[{ }^{\wedge} \mathrm{RKC}\right]\{0,6\}$ ' and only contigs with 5-fold coverage were kept for the subsequent analyses. The pool of extracted toxins from the SRA-data were used as tblastnqueries in two additional iterations of toxin identification.

In addition to the identified toxins, we also used signaling SSRP-like peptides from annelids, molluscs and vertebrates in the analysis. These were modified to only have two amino acid residues preceding the cysteine-ring to match the structure of the toxin-sequences in this analysis.

665 We extracted the length, molecular weight, aromaticity, and isoelectric point, as well as the count for the 150 most common 1-3mers across all the sequences. Principal components were calculated using the sklearn library v 0.24.1 (Pedregosa et al. 2011) in Python 3.6.9 on data scaled to remove the mean and unit variance. The two first principal components were used to visualize the sequences using R 3.6.3 with the library tidyverse 1.3.1 (Wickham et al. 2019).

\section{Peptide synthesis}

Ct-SSRPL1 predicted from the whole-body transcriptome of the annelid C. teleta was synthesized by solid-phase peptide synthesis (SPPS) in 0.1 mmol scale using preloaded FmocTrp Tentagel R HMPA resin from Rapp Polymere (Tuebingen, Germany). The sequence was 675 H-ZASSGAQICIWKVCPPTPW-OH, where Z represents a pyroglutamic acid and Cys9 and Cys 14 are connected by a disulfide bond. Fmoc-protected amino acids, coupling reagents and solvents used for the synthesis were purchased from Iris Biotech (Marktredwitz, Germany). The synthesis was performed on a Syro I instrument from Biotage (Uppsala, Sweden). Coupling conditions were room temperature for 2 x $120 \mathrm{~min}$ using $5.2 \mathrm{eq}$ amino acids, 4.7 eq $N$-[(1H-benzotriazol-1-yl)(dimethylamino)methylene]- $N$-methylmethanaminium 
hexafluorophosphate $N$-oxide (HBTU), 5.2 eq 1-hydroxy-7-azabenzotriazol (HOAt), and 8 eq $\mathrm{N}, \mathrm{N}$-diisopropylethylamine (DIPEA) in dimethylformamide (DMF) relative to resin. Deprotection was performed at room temperature with $40 \%$ piperidine in DMF for 3 min followed by $20 \%$ piperidine in DMF for 15 min. Washing steps were with 2 x N-methyl-2pyrrolidone (NMP), $1 \mathrm{x}$ dichloromethane (DCM), and $1 \mathrm{x}$ DMF. After completion of the peptide assembly, the peptidyl-resin was washed with $3 \times$ DCM and dried. The peptide was released from approximately $0.05 \mathrm{mmol}$ of resin using a mixture $(3 \mathrm{~mL})$ of $95 \%$ trifluoroacetic acid (TFA), $2.5 \%$ triethylsilyl (TES), and $2.5 \%$ water over $2.5 \mathrm{~h}$. Cold diethylether $(15 \mathrm{~mL}$ at $20{ }^{\circ} \mathrm{C}$ ) was added and the mixture further cooled to $-85^{\circ} \mathrm{C}$ for $30 \mathrm{~min}$ before the peptide was

690 isolated by centrifugation. The peptide was redissolved in a mixture of acetic acid, water, and acetonitrile $(\mathrm{ACN})$ in volume ratios of 1:10:4 and freeze dried to remove unwanted carboxylation of Trp. The freeze dried compound was resuspended in $1 \%$ vol/vol TFA and water. $0.1 \mathrm{M}$ phosphate buffer and appr. ACN (3 mL) was added to $10 \mathrm{~mL}$ to this mixture. The $\mathrm{pH}$ was adjusted to 6 using $1 \mathrm{M}$ hydrochloride acid $(\mathrm{HCl})$. Dimethyl sulfoxide (DMSO, 1.0 $\mathrm{mL})$ was added $(10 \% \mathrm{~V} / \mathrm{V})$ and the mixture was stirred for $20 \mathrm{~h}$ at room temperature to allow disulfide bond formation. The mixture was filtered and directly purified on a Dionex Ultimate 3000 HPLC system (Thermo Fisher, Waltham, USA) using a Luna C18(2) column from Phenomenex (Torrance, USA, $5 \mu \mathrm{m}, 100 \AA, 250 \times 10 \mathrm{~mm}$ ). A gradient of $5 \%-100 \% \mathrm{ACN}$ in water $/ 0.1 \%$ formic acid was applied. The product was isolated and lyophilized by freeze drying to yield appr. $3.5 \mathrm{mg}(0.0017 \mathrm{mmol})$. The final product was analyzed by liquid chromatography (LC)-mass spectrometry (MS) on a Dionex Ultimate 3000 ultra high performance LC (UHPLC) system from Thermo Fisher connected to an Impact HD mass spectrometer (Bruker, Bremen, Germany). The calculated monoisotopic $\mathrm{MH}^{+1}$ of the purified product was 2052.97 (detected monoisotopic $\mathrm{MH}^{+1}:$ 2053.00) (Figure S4A).

705 Cr-SSRPL1 predicted from the nerve ring transcriptome of the cone snail C. rolani was custom synthesized by GenScript (Leiden, Netherlands). The sequence was HSGGMSLCLWKVCPAAPWLVS-OH, where Cys7 and Cys12 are connected by a disulfide bond. The folded peptide was purified to $>95 \%$ by HPLC analysis and verified by MS. The calculated monoisotopic $\mathrm{MH}^{+1}$ of the purified product was 2103.02 (detected monoisotopic $\mathrm{MH}^{+1}$ : 2103.39) (Figure S4B). 


\section{GPCR assays}

Unless otherwise stated, all chemicals used for cell culture were from Sigma-Aldrich (Burlington, MA, USA), and all medium and buffers are from ThermoFisher Scientific (Waltham, MA, USA).

HTLA cells (a kind gift from Prof. Hans Bräuner-Osborne) were maintained in DMEM 720 supplemented with $10 \%$ FBS (Biowest, Nuaillé, Franc), $100 \mathrm{U} / \mathrm{mL}$ penicillin and $100 \mu \mathrm{g} / \mathrm{mL}$ streptomycin, as well as $100 \mu \mathrm{g} / \mathrm{mL}$ hygromycin B and $2 \mu \mathrm{g} / \mathrm{mL}$ puromycin (growth medium) and detached by washing with $\mathrm{Ca}^{2+}$ - and $\mathrm{Mg}^{2+}$-free PBS (Substrate Department, University of Copenhagen, DK). One million cells per well were seeded in 6 well plates in $2 \mathrm{~mL}$ growth medium the day before transfection and transfected with PolyFect (Qiagen, Düsseldorf, DE)

725 using the manufacturers protocol (changing the medium to growth medium without hygromycin B and puromycin prior to transfection). 15,000 transfected cells per well were seeded in polyD-lysine coated white clear bottom 384 well plates (Corning New York, NY, USA) in $40 \mu \mathrm{L}$ DMEM supplemented with $1 \%$ dFBS (ThermoFisher) (assay medium) and incubated overnight. The next day, medium was changed to $40 \mu \mathrm{L}$ fresh assay medium, and compounds

730 were added at $5 \mathrm{x}$ concentration in $10 \mu \mathrm{L}$ HBSS supplemented with $1 \mathrm{mM} \mathrm{CaCl}_{2}, 1 \mathrm{mM} \mathrm{MgCl}_{2}$, $20 \mathrm{mM}$ HEPES, pH adjusted to 7.4 with $10 \mathrm{M} \mathrm{NaOH}$ (assay buffer) with $0.1 \%$ BSA added and sterile $(0.2 \mu \mathrm{M})$ filtered, and cells were incubated overnight. The next day, the compounds were removed, and the cells incubated for 20 minutes in $20 \mu \mathrm{L}$ of assay buffer with $0.01 \%$ pluronic F-68 (ThermoFisher) and $5 \%$ BrightGlo (Promega, Madison, WI, USA) before reading

735 luminescence on a Molecular Devices SpectraMax iD5 with a 1 second integration time. Data was analyzed using GraphPad Prism 9 (San Diego, CA, USA). Concentration response curves were fitted to a four-parameter dose-response curve. 


\section{References}

Ahorukomeye P, Disotuar MM, Gajewiak G, Karanth S, Watkins M, Robinson SD, Flórez Salcedo P, Smith NA, Smith BJ, Schlegel A et al. 2019. Fish-hunting cone snail venoms are a rich source of minimized ligands of the vertebrate insulin receptor. eLIFE. Feb 14, 2019.

745 Almagro Armenteros JJ, Tsirigos KD, Sønderby CK, Petersen TN, Winther O, Brunak S, von Heijne G, Nielsen H. 2019. Signalp 5.0 improves signal peptide predictions using deep neural networks. Nature Biotechnology. 37(4):420-423.

Aman JW, Imperial JS, Ueberheide B, Zhang MM, Aguilar M, Taylor D, Watkins M, Yoshikami D, Showers-Corneli P, Safavi-Hemami H et al. 2015. Insights into the origins of fish hunting in venomous cone snails from studies of conus tessulatus. Proc Natl Acad Sci U S A. 112(16):5087-5092.

Brazeau P, Vale W, Burgus R, Ling N, Butcher M, Rivier J, Guillemin R. 1973. Hypothalamic polypeptide that inhibits the secretion of immunoreactive pituitary growth hormone. Science. 179(4068):77-79.

Cannon JT, Vellutini BC, Smith J, Ronquist F, Jondelius U, Hejnol A. 2016. Xenacoelomorpha is the sister group to nephrozoa. Nature. 530(7588):89-93.

Chen S, Zhou Y, Chen Y, Gu J. 2018. Fastp: An ultra-fast all-in-one fastq preprocessor. Bioinformatics. 34(17):i884-i890.

Chernomor O, von Haeseler A, Minh BQ. 2016. Terrace aware data structure for phylogenomic inference from supermatrices. Systematic Biology. 65(6):997-1008.

Cruz LJ, de Santos V, Zafaralla GC, Ramilo CA, Zeikus R, Gray WR, Olivera BM. 1987. Invertebrate vasopressin/oxytocin homologs. Characterization of peptides from conus geographus and conus striatus venoms. The Journal of biological chemistry. 262(33):15821-15824.

765 Deghenghi R, Papotti M, Ghigo E, Muccioli G. 2001. Cortistatin, but not somatostatin, binds to growth hormone secretagogue (ghs) receptors of human pituitary gland. J Endocrinol Invest. 24(1):Rc1-3.

Duda TF, Jr., Kohn AJ, Palumbi S. 2001. Origins of diverse feeding ecologies within conus, a genus of venomous marine gastropods. Biological Journal of the Linnean Society.

Elphick MR, Mirabeau O, Larhammar D. 2018. Evolution of neuropeptide signalling systems. The Journal of experimental biology. 221(Pt 3).

Grabherr MG, Haas BJ, Yassour M, Levin JZ, Thompson DA, Amit I, Adiconis X, Fan L, Raychowdhury R, Zeng Q et al. 2011. Full-length transcriptome assembly from rna-seq data without a reference genome. Nat Biotechnol. 29(7):644-652.

Grimmelikhuijzen CJP, Hauser F. 2012. Mini-review: The evolution of neuropeptide signaling. Regul Pept. 177 Suppl:S6-9.

Haas BJ, Papanicolaou A, Yassour M, Grabherr M, Blood PD, Bowden J, Couger MB, Eccles D, Li B, Lieber M et al. 2013. De novo transcript sequence reconstruction from rna-seq using the trinity platform for reference generation and analysis. Nature Protocols. 8(8):1494-1512.

Hejnol A, Pang K. 2016. Xenacoelomorpha's significance for understanding bilaterian evolution. Current Opinion in Genetics \& Development. 39:48-54.

785 Bioinformatics. 17(8):754-755.

Jékely G. 2013. Global view of the evolution and diversity of metazoan neuropeptide signaling. Proceedings of the National Academy of Sciences. 110(21):8702-8707.

Jondelius U, Raikova OI, Martinez P. 2019. Xenacoelomorpha, a key group to understand bilaterian evolution: Morphological and molecular perspectives. In: Pontarotti P, editor. 
Evolution, origin of life, concepts and methods. Cham: Springer International Publishing. p. 287-315.

Kapli P, Telford MJ. 2020. Topology-dependent asymmetry in systematic errors affects phylogenetic placement of ctenophora and xenacoelomorpha. Science Advances. 6(50):eabc5162.

795 Kapustin Y, Souvorov A, Tatusova T, Lipman D. 2008. Splign: Algorithms for computing spliced alignments with identification of paralogs. Biology Direct. 3(1):20.

Katoh K, Standley DM. 2013. Mafft multiple sequence alignment software version 7: Improvements in performance and usability. Molecular biology and evolution. 30(4):772-780.

800 Kohn AJ. 1956. Piscivorous gastropods of the genus conus. Proceedings of the National Academy of Sciences of the United States of America. 42(3):168-171.

Li B, Dewey CN. 2011. Rsem: Accurate transcript quantification from rna-seq data with or without a reference genome. BMC Bioinformatics. 12(1):323.

Li Q, Barghi N, Lu A, Fedosov AE, Bandyopadhyay PK, Lluisma AO, Concepcion GP, Yandell M, Olivera BM, Safavi-Hemami H. 2017. Divergence of the venom exogene repertoire in two sister species of turriconus. Genome biology and evolution. 9(9):2211-2225.

Madeira F, Park YM, Lee J, Buso N, Gur T, Madhusoodanan N, Basutkar P, Tivey ARN, Potter SC, Finn RD et al. 2019. The embl-ebi search and sequence analysis tools apis in 2019. Nucleic Acids Res. 47(W1):W636-W641.

810 Mair GR, Halton DW, Shaw C, Maule AG. 2000. The neuropeptide f (npf) encoding gene from the cestode, moniezia expansa. Parasitology. 120(1):71-77.

Martín-Durán JM, Vellutini BC, Marlétaz F, Cetrangolo V, Cvetesic N, Thiel D, Henriet S, Grau-Bové X, Carrillo-Baltodano AM, Gu W et al. 2021. Conservative route to genome compaction in a miniature annelid. Nat Ecol Evol. 5(2):231-242.

815 Martinez V. 2015. Handbook of biologically active peptides. copyright (C) 2013 elsevier inc. All rights reserved. In: Takei Y, Ando H, Tsutsui K, editors. Elsevier. p. 1320-1329.

Mayrose I, Graur D, Ben-Tal N, Pupko T. 2004. Comparison of site-specific rate-inference methods for protein sequences: Empirical bayesian methods are superior. Molecular biology and evolution. 21(9):1781-1791.

820 Menting JG, Gajewiak J, MacRaild CA, Chou DH, Disotuar MM, Smith NA, Miller C, Erchegyi J, Rivier JE, Olivera BM et al. 2016. A minimized human insulin-receptorbinding motif revealed in a conus geographus venom insulin. Nature structural \& molecular biology. 23(10):916-920.

Mirabeau O, Joly J-S. 2013. Molecular evolution of peptidergic signaling systems in bilaterians. Proceedings of the National Academy of Sciences. 110(22):E2028-E2037.

Moller LN, Stidsen CE, Hartmann B, Holst JJ. 2003. Somatostatin receptors. Biochimica et biophysica acta. 1616(1):1-84.

Nguyen L-T, Schmidt HA, von Haeseler A, Minh BQ. 2015. Iq-tree: A fast and effective stochastic algorithm for estimating maximum-likelihood phylogenies. Molecular biology and evolution. 32(1):268-274.

Nybakken J, Perron FE. 1988. Ontogenetic change in the radula of conus magus (gastropoda). Marine Biology. 98:239-242.

Olivera BM, Seger J, Horvath MP, Fedosov AE. 2015. Prey-capture strategies of fish-hunting cone snails: Behavior, neurobiology and evolution. Brain, behavior and evolution. 86(1):58-74.

Ong KL, Wong LY, Cheung BM. 2008. The role of urotensin ii in the metabolic syndrome. Peptides. 29(5):859-867. 
Pedregosa F, Varoquaux Ge, 1, Gramfort A, Michel V, Thirion B, Grisel O, Blondel M, Prettenhofer P, Weiss R, Dubourg V et al. 2011. Scikit-learn: Machine learning in python. Journal of Machine Learning Research. 12(Oct):2825--2830.

Phuong MA, Alfaro ME, Mahardika GN, Marwoto RM, Prabowo RE, von Rintelen T, Vogt PWH, Hendricks JR, Puillandre N. 2019. Lack of signal for the impact of conotoxin gene diversity on speciation rates in cone snails. Syst Biol. 68(5):781-796.

Pless J. 2005. The history of somatostatin analogs. J Endocrinol Invest. 28(11 Suppl International): $1-4$.

Puillandre N, Bouchet P, Duda TF, Jr., Kauferstein S, Kohn AJ, Olivera BM, Watkins M, Meyer C. 2014. Molecular phylogeny and evolution of the cone snails (gastropoda, conoidea). Molecular phylogenetics and evolution. 78:290-303.

Ramiro IBL, Bjørn-Yoshimoto WE, Imperial JS, Gajewiak J, Watkins M, Taylor D, Resager W, Ueberheide B, Bräuner-Osborne H, Whitby FG et al. 2021. Somatostatin venom analogs evolved by fish-hunting cone snails: From prey capture behavior to identifying drug leads. bioRxiv.2021.2010.2026.465842.

Robas N, Mead E, Fidock M. 2003. Mrgx2 is a high potency cortistatin receptor expressed in dorsal root ganglion. J Biol Chem. 278(45):44400-44404.

855 Romanova EV, Sasaki K, Alexeeva V, Vilim FS, Jing J, Richmond TA, Weiss KR, Sweedler JV. 2012. Urotensin ii in invertebrates: From structure to function in aplysia californica. PloS one. 7(11):e48764.

Ronquist F, Huelsenbeck JP. 2003. Mrbayes 3: Bayesian phylogenetic inference under mixed models. Bioinformatics. 19(12):1572-1574.

860 Safavi-Hemami H, Lu A, Li Q, Fedosov AE, Biggs J, Showers Corneli P, Seger J, Yandell M, Olivera BM. 2016. Venom insulins of cone snails diversify rapidly and track prey taxa. Molecular biology and evolution. 33(11):2924-2934.

Schmieder R, Edwards R. 2011. Quality control and preprocessing of metagenomic datasets. Bioinformatics. 27(6):863-864.

865 Semmens DC, Mirabeau O, Moghul I, Pancholi MR, Wurm Y, Elphick MR. 2016. Transcriptomic identification of starfish neuropeptide precursors yields new insights into neuropeptide evolution. Open biology. 6(2):150224.

Sievers F, Wilm A, Dineen D, Gibson TJ, Karplus K, Li W, Lopez R, McWilliam H, Remmert M, Söding $\mathbf{J}$ et al. 2011. Fast, scalable generation of high-quality protein multiple sequence alignments using clustal omega. Molecular Systems Biology. 7(1):539.

Suyama M, Torrents D, Bork P. 2006. Pal2nal: Robust conversion of protein sequence alignments into the corresponding codon alignments. Nucleic Acids Res. 34(Web Server issue):W609-612.

Tostivint H, Ocampo Daza D, Bergqvist CA, Quan FB, Bougerol M, Lihrmann I, Larhammar D. 2014. Molecular evolution of gpcrs: Somatostatin/urotensin ii receptors. Journal of molecular endocrinology. 52(3):T61-86.

Vaudry H, Do Rego JC, Le Mevel JC, Chatenet D, Tostivint H, Fournier A, Tonon MC, Pelletier G, Conlon JM, Leprince J. 2010. Urotensin ii, from fish to human. Ann N Y Acad Sci. 1200:53-66.

880 Veenstra JA. 2009. Allatostatin c and its paralog allatostatin double c: The arthropod somatostatins. Insect Biochem Mol Biol. 39(3):161-170.

Wickham H, Averick M, Bryan J, Chang W, McGowan L, François R, Grolemund G, Hayes A, Henry L, Hester J et al. 2019. Welcome to the tidyverse. Journal of Open Source Software. 4:1686.

885 Woodward SR, Cruz LJ, Olivera BM, Hillyard DR. 1990. Constant and hypervariable regions in conotoxin propeptides. Embo Journal. 9(4):1015-1020. 
Xiong X, Blakely B, Kim JH, Menting J, Schubert HL, R. A, T. G, I.B. S, Delaine C, Y.W. Z et al. 2021. Visualization of insulin receptor activation by a novel insulin analog with elongated a chain and truncated $b$ chain. Nature Chemical Biology. in review.

Xiong X, Menting JG, Disotuar MM, Smith NA, Delaine CA, Ghabash G, Agrawal R, Wang X, He X, Fisher SJ et al. 2020. A structurally minimized yet fully active insulin based on cone-snail venom insulin principles. Nature structural \& molecular biology. 27(7):615-624.

Yañez-Guerra LA, Zhong X, Moghul I, Butts T, Zampronio CG, Jones AM, Mirabeau O, Elphick MR. 2020. Echinoderms provide missing link in the evolution of prrp/snpf-type neuropeptide signalling. eLife. 9:e57640.

Yang Z. 2007. Paml 4: Phylogenetic analysis by maximum likelihood. Molecular biology and evolution. 24(8):1586-1591.

Zakas C, Harry ND, Scholl EH, Rockman MV. 2021. The genome of the poecilogonous annelid streblospio benedicti. bioRXiv.

Zhang M, Wang Y, Li Y, Li W, Li R, Xie X, Wang S, Hu X, Zhang L, Bao Z. 2018. Identification and characterization of neuropeptides by transcriptome and proteome analyses in a bivalve mollusc patinopecten yessoensis. Front Genet. 9:197-197.

Zhang Y, Yañez Guerra LA, Egertová M, Zampronio CG, Jones AM, Elphick MR. 2020. Molecular and functional characterization of somatostatin-type signalling in a deuterostome invertebrate. Open biology. 10(9):200172. 


\section{Supporting Figures}

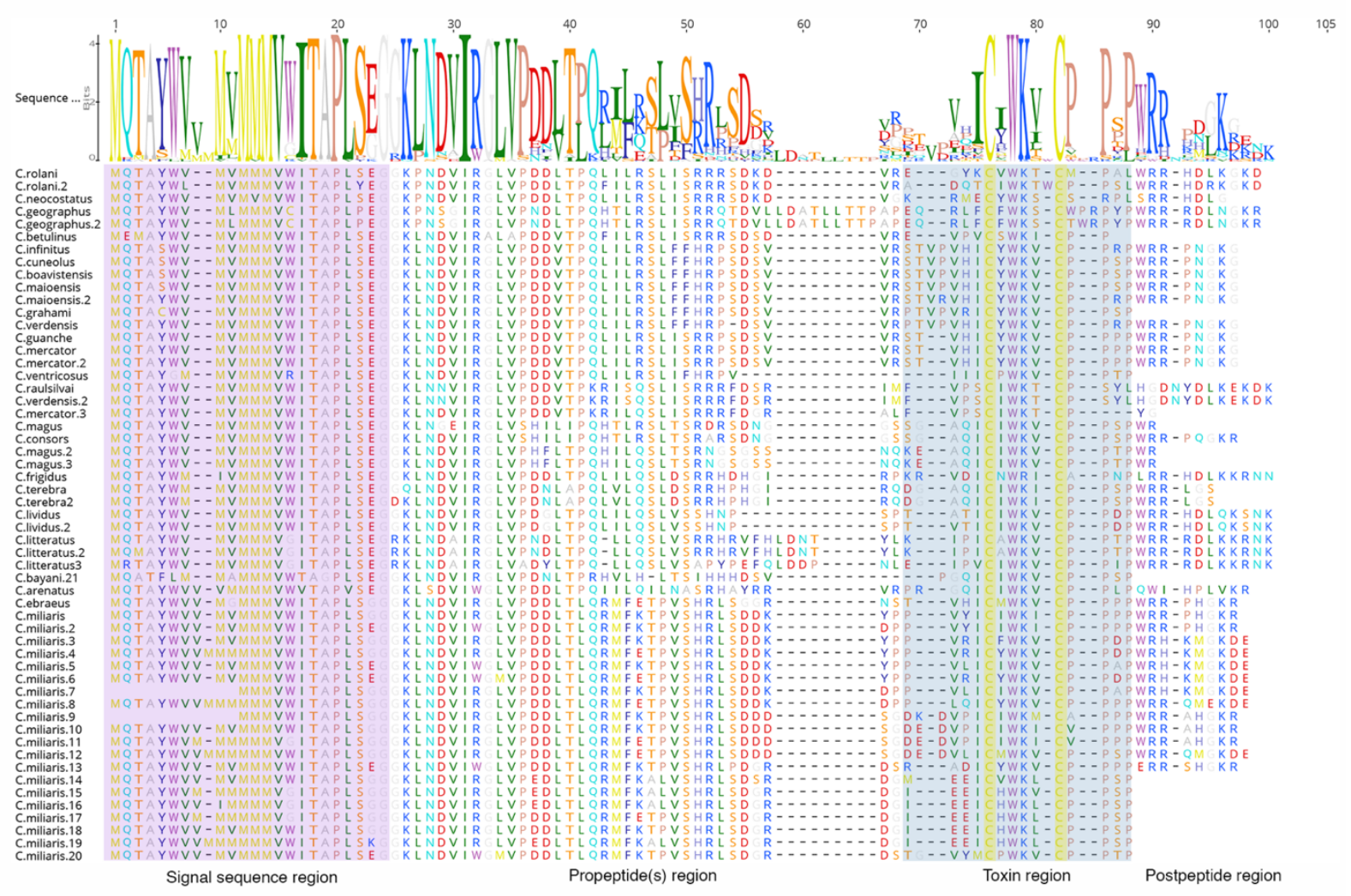

Figure S1. Multiple sequence alignment of consomatins identified in the venom gland transcriptomes of diverse cone snail species. Color coding as shown in Figure 2. Sequence logos were created using Geneious software (version R11). 
A

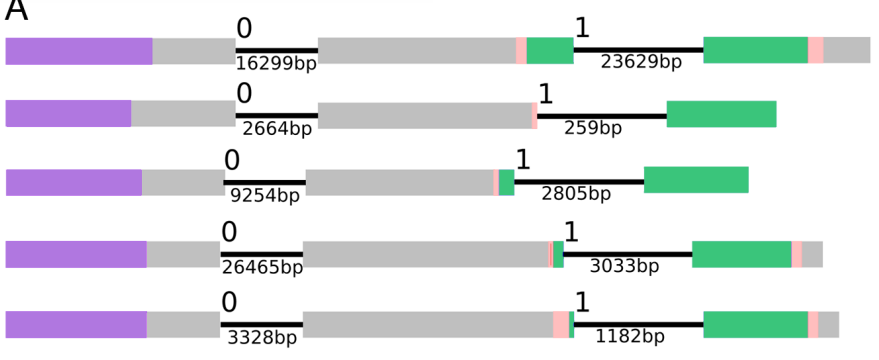

B

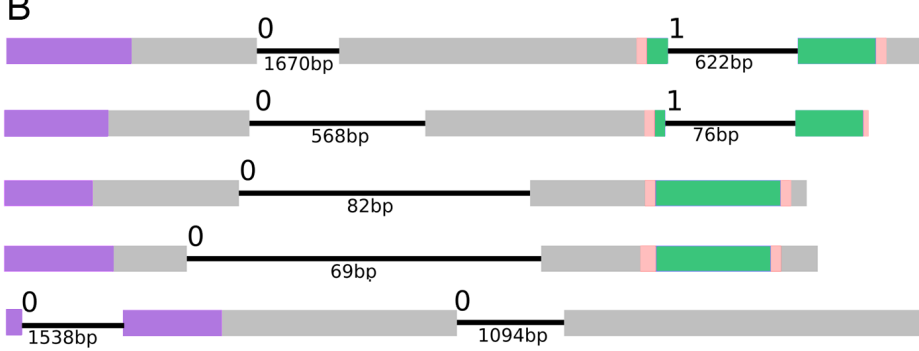

C

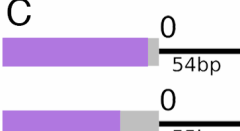

$\frac{0}{54 \mathrm{bp}}$

$\frac{0}{55 b p}$

$\frac{1}{57 \mathrm{bp}}$

1

$\mathrm{D}$

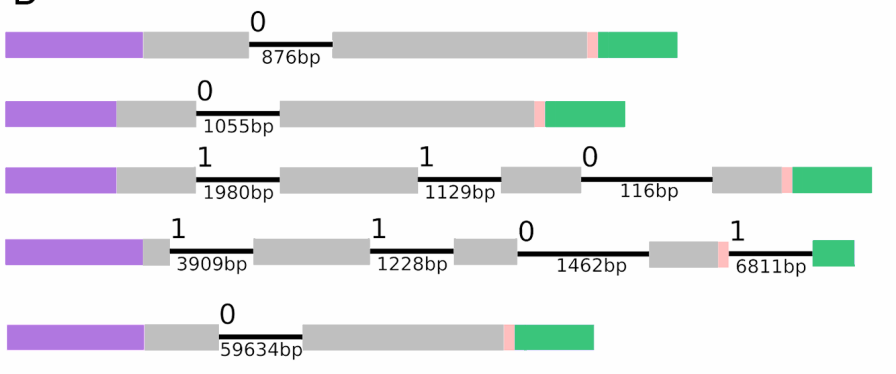

Gigantopelta aegis SSRP-like 1

Crassostrea virginica SSRP-like 1

Octopus sinestris SSRP-like 1

Pomacea canaliculata SSRP-like splice variant 1

Pomacea canaliculata SSRP-like splice variant 2

Capitella teleta SSRP-like 1

Dinophilus gyrociliatus SSRP-like 1

Dinophilus gyrociliatus SSRP-like 2

Dinophilus gyrociliatus SSRP-like 3

1

Rotifera sordia SSRP-like 1

Rotifera socialis SSRP-like 1

Homo sapiens SS

Homo sapiens CST

Homo sapiens UII

Homo sapiens URP

Asterias rubens ArSS2

Figure S2. Gene structures of SSRP-like genes in (A) Mollusca, (B) Annelida, (C) Rotifera, and (D) Deuterostomes (human and starfish). Colors are according to figure 2; signal sequence (purple), propeptides (gray), mature toxin region (blue), mature signaling SSRP-like peptide region (green), and postpeptides (gray). 
bioRxiv preprint doi: https://doi.org/10.1101/2021.11.05.463867; this version posted November 6, 2021. The copyright holder for this preprint (which was not certified by peer review) is the author/funder, who has granted bioRxiv a license to display the preprint in perpetuity. It is made available under aCC-BY-NC 4.0 International license.

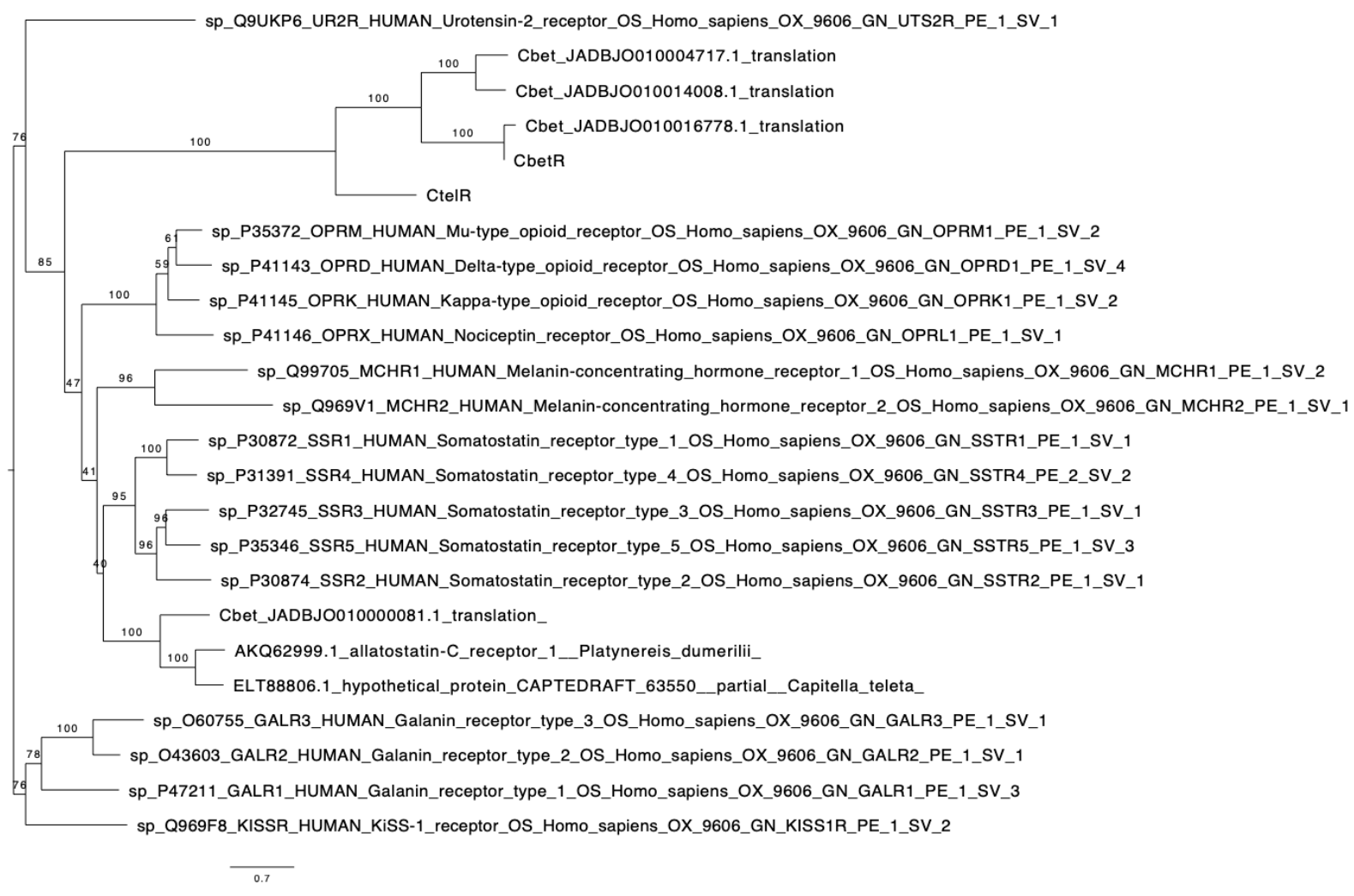

Figure S3. Maximum likelihood tree of SSRP-receptors from human, AST-C receptor from Platynereis dumerilii and putative receptors from Conus betulinus and Capitella teleta. The tree 925 is a full version of Figure 5A in the main text. The bootstrap values were calculated with 1000 replicated from IQ-Tree's UF-bootstrap method. 


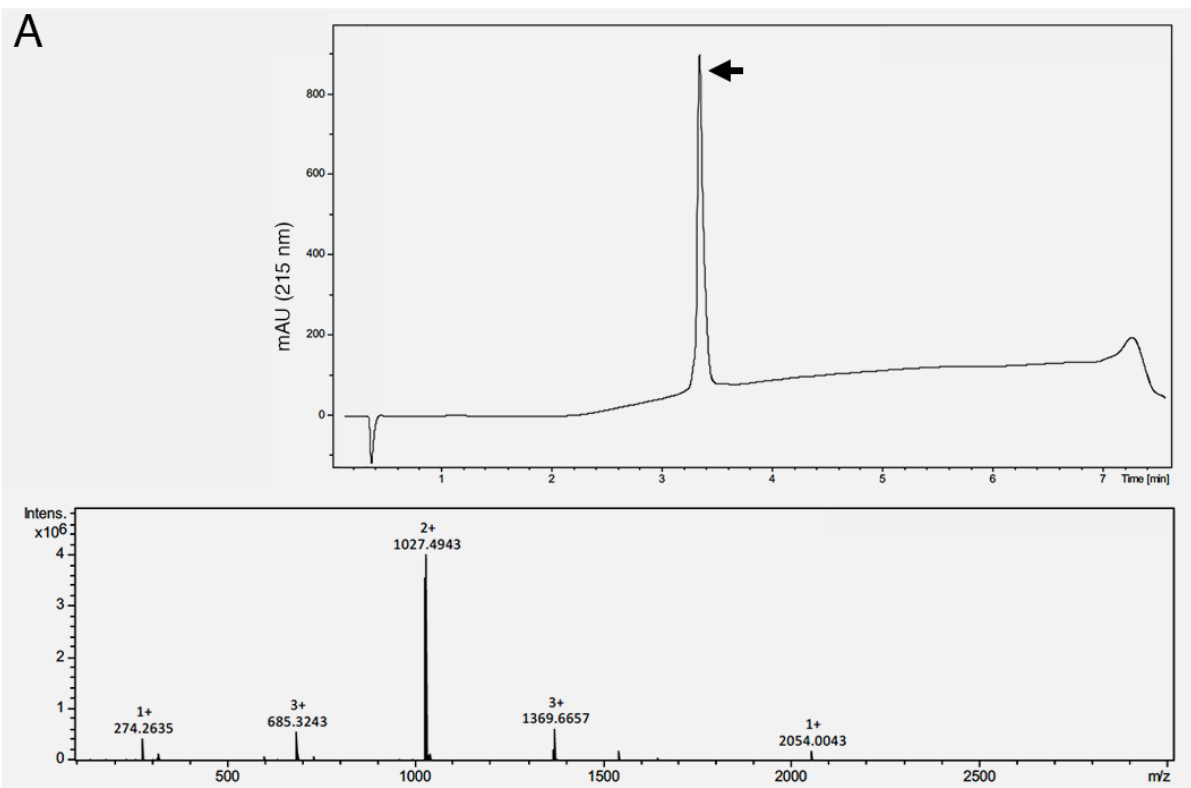

B

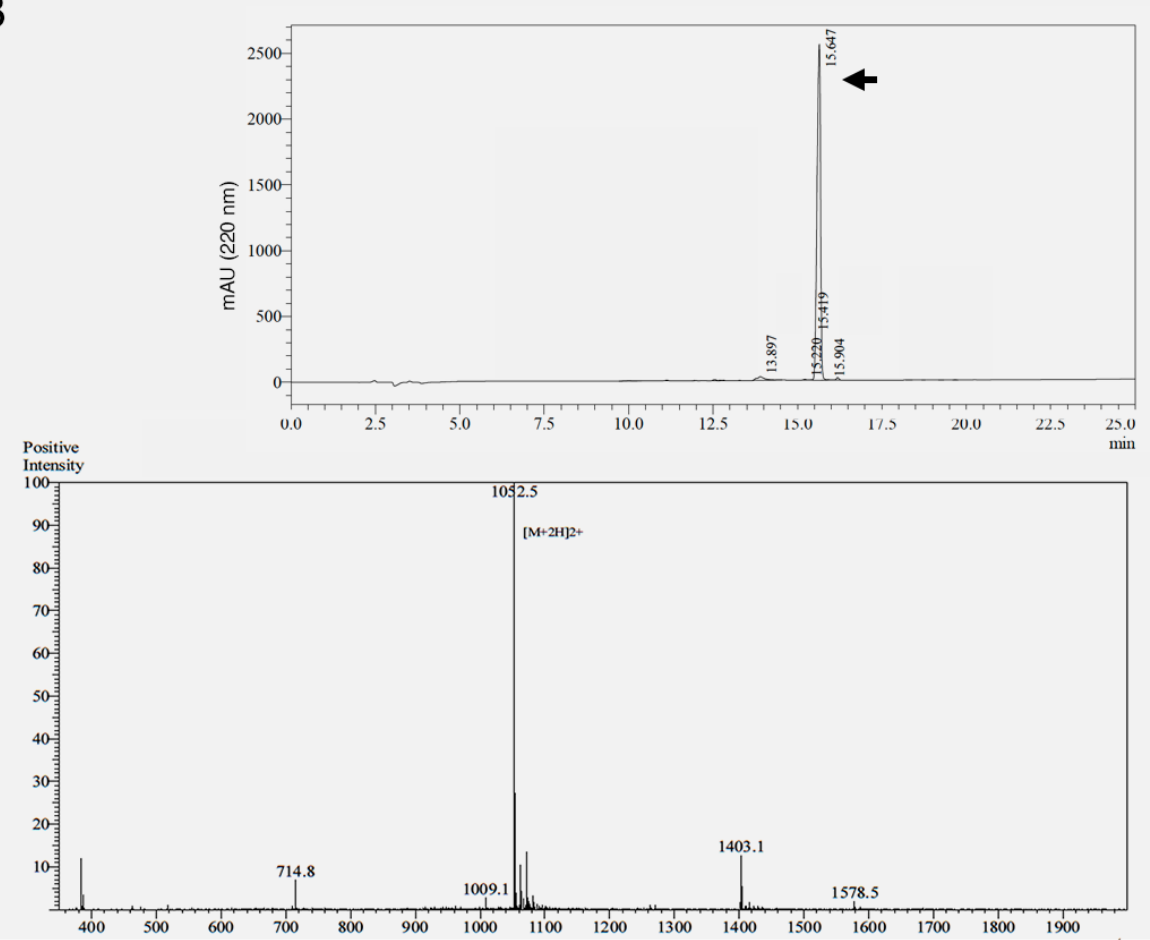

Figure S4. Quality control of synthetic (A) Ct-SSRPL1 from the annelid Capitella teleta and

(B) Cr-SSRPL1 from Conus rolani. Peptides were synthesized using solid-phase synthesis as described in material and methods. The purity and integrity of the peptides was analyzed by reversed-phase high performance liquid chromatography (HPLC, upper panel) and mass spectrometry (MS/MS, lower panel) of the main HPLC peaks (black arrows). 


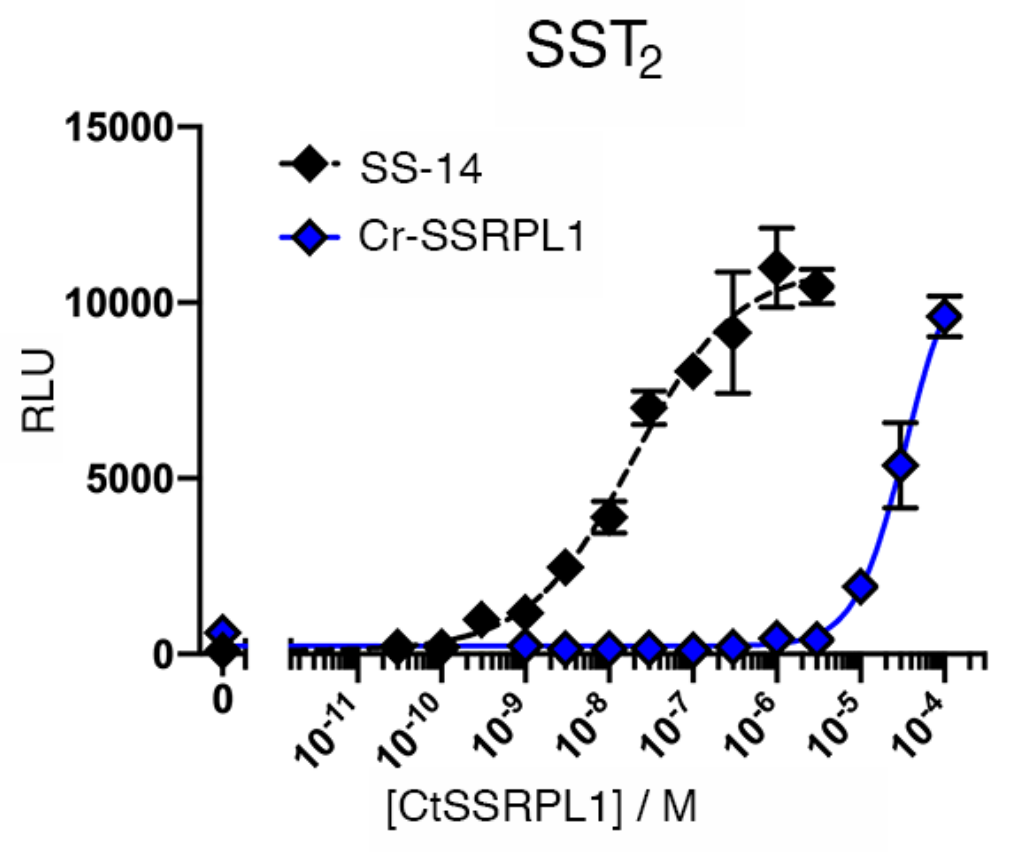

Figure S5. Concentration-response curve of human somatostatin-14 (SS) and the Conus rolani nerve ring SSRP-like peptide (Cr-SSRPL1) at the human somatostatin receptor $2\left(\mathrm{SST}_{2}\right)$ in the PRESTO-Tango assay (error bars represent SD), showing an activation by Cr-SSRPL1 at 940 micromolar concentrations. 